\title{
Niche and neutral assembly mechanisms contribute to latitudinal diversity gradients in reef fishes
}

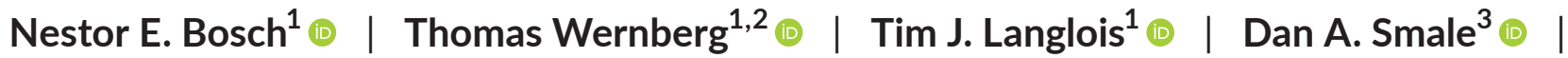 \\ ${\text { Pippa J. Moore }{ }^{4} \odot \text { | João N. Franco }{ }^{5,6}{ }_{\odot} \mid \text { Pierre Thiriet }^{7,8}{ }^{\infty} \text { | Eric Feunteun }}^{9}$ |

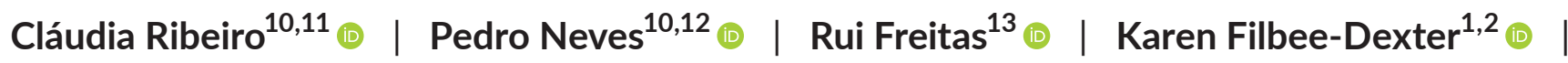 \\ Kjell Magnus Norderhaug ${ }^{2} \odot$ | Alvaro Garcia ${ }^{14}$ | Francisco Otero-Ferrer ${ }^{14}$ (i) |

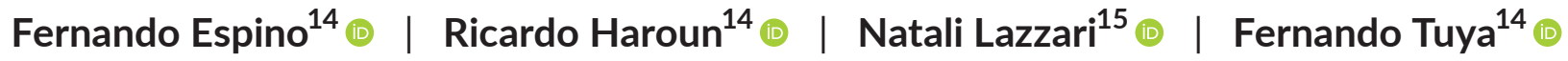

\footnotetext{
${ }^{1}$ The UWA Oceans Institute, School of Biological Sciences, The University of Western Australia, Crawley, Western Australia, Australia

${ }^{2}$ Institute of Marine Research, His, Norway

${ }^{3}$ The Laboratory, Marine Biological Association of the United Kingdom, Plymouth, UK

${ }^{4}$ School of Natural and Environmental Sciences, Newcastle University, Newcastle upon Tyne, UK

${ }^{6}$ CIIMAR/CIMAR-Interdisciplinary Centre of Marine and Environmental Research, University of Porto, Matosinhos, Portugal

${ }^{7}$ UMS 2006 Patrimoine Naturel (OFB, CNRS, MNHN)-CRESCO, Dinard, France

${ }^{8}$ Museum National d'Histoire Naturelle, Station Marine de Dinard-CRESCO, Dinard, France

${ }^{9}$ Museum National d'Histoire Naturelle, BOREA (MNHN, CNRS, Sorbonne Université, IRD, UniCaen, Univ Antilles Guadeloupe), Dinard, France

${ }^{10}$ Observatório Oceânico da Madeira, Agência Regional para o Desenvolvimento da Investigação, Tecnologia e Inovação (OOM/ARDITI), Funchal, Portugal

${ }^{12}$ Marine Plant Ecology Research Group, Centre of Marine Sciences (CCMAR), Faro, Portugal

${ }^{13}$ Instituto de Engenharia e Ciências do Mar, Universidade Técnica do Atlântico, Mindelo, Cabo Verde

${ }^{14}$ Grupo en Biodiversidad y Conservación, IU-ECOAQUA, Universidad de Las Palmas de Gran Canaria, Telde, Spain
} \\ ${ }^{5}$ MARE-Marine and Environmental Sciences Centre, ESTM, Politécnico de Leiria, Peniche, Portugal \\ ${ }^{11}$ Instituto das Florestas e Conservação da Natureza, IP-RAM, Jardim Botânico da Madeira-Eng.o Rui Vieira, Funchal, Portugal \\ ${ }^{15}$ Theoretical and Computational Ecology Laboratory, Center for Advanced Studies of Blanes (CEAB-CSIC), Gerona, Spain
}

\section{Correspondence}

Nestor E. Bosch, The UWA Oceans Institute, School of Biological Sciences,

The University of Western Australia, 35

Stirling Highway, Crawley, 6009 WA,

Australia.

Email: nbosch1989@gmail.com

Funding information

Fundação para a Ciência e a

Tecnologia, Grant/Award Number:

UIDB/04326/2020; Oceanic Observatory of Madeira Project, Grant/Award Number: M1420-01-0145-FEDER-000001; UKRI

Future Leaders Fellowship, Grant/Award Number: MR/S032827/1; Marie Curie

Career Integration Grant, Grant/Award

Number: PCIG10-GA-2011-303685;

Australian Research Council, Grant/Award

Number: DP170100023

Handling Editor: Werner Ulrich

\section{Abstract}

Aim: The influence of niche and neutral mechanisms on the assembly of ecological communities have long been debated. However, we still have a limited knowledge on their relative importance to explain patterns of diversity across latitudinal gradients (LDG). Here, we investigate the extent to which these ecological mechanisms contribute to the LDG of reef fishes.

Location: Eastern Atlantic Ocean.

Taxon: Reef-associated ray-finned fishes.

Methods: We combined abundance data across $\sim 60^{\circ}$ of latitude with functional trait data and phylogenetic trees. A null model approach was used to decouple the influence of taxonomic diversity (TD) on functional (FD) and phylogenetic (PD) diversity. Standardized effect sizes (SES FD and SES PD) were used to explore patterns of overdispersion, clustering and randomness. Information theoretic approaches were used to investigate the role of large- (temperature, geographic isolation, nitrate and net primary productivity) and local-scale (human population and depth) drivers. We 
further assessed the role of demographic stochasticity and its interaction with species trophic identity and dispersal capacity.

Results: Taxonomic diversity peaked at $\sim 15^{\circ}-20^{\circ} \mathrm{N}$, with a second mode of lower magnitude at $\sim 45^{\circ} \mathrm{N}$; a pattern that was predicted by temperature, geographic isolation and productivity. Tropical regions displayed a higher proportion of overdispersed assemblages, whilst clustering increased towards temperate regions. Phylogenetic and functional overdispersion were associated with warmer, productive and isolated regions. Demographic stochasticity also contributed largely to community assembly, independently of ecoregions, although variation was dependent on the trophic identity and body size of species.

Main conclusions: Niche-based processes linking thermal and resource constraints to local coexistence mechanisms have contributed to the LDG in reef fishes. These processes do not act in isolation, stressing the importance of understanding interactions between deterministic and stochastic factors driving community structure in the face of rapid biodiversity change.

\section{KEYWORDS}

demographic stochasticity, dispersal limitation, environmental filtering, limiting similarity, niche partitioning, trophic drivers

\section{1 | INTRODUCTION}

Understanding the processes that structure biodiversity along largescale environmental gradients is a core challenge in ecology and evolutionary biology (Gaston, 2000). Among the most universal ecological paradigms, the latitudinal diversity gradient (LDG) predicts that species diversity (taxonomic diversity, TD) sharply declines from the tropics towards the poles (Willig et al., 2003), a pattern that has received empirical support for a wide range of marine and terrestrial organisms (Edgar et al., 2017; Hillebrand, 2004; Tittensor et al., 2010). Numerous evolutionary and ecological mechanisms have been suggested to generate and maintain the current LDG (e.g. Brown, 2014), with recent developments of eco-evolutionary mechanistic models shedding light on the relative importance of these processes over geological and ecological time-scales (Gaboriau et al., 2019).

At the forefront of the debate on mechanisms underpinning the LDG, is the relative importance of processes that shape community dynamics (i.e. selection, ecological drift and dispersal; Vellend, 2010), and how they interact with regional-scale process (i.e. speciation) to determine the diversity, composition and structure of local assemblages (Ricklefs, 1987). Early synthesis in community ecology focused on the concept of niche (Hutchinson, 1957), whereby deterministic fitness differences between species in response to abiotic (i.e. 'environmental filtering') and biotic (i.e. 'limiting similarity') factors determine which species from the regional pool are able to coexist in a local community, and their relative abundances (Macarthur \& Levins, 1967). In contrast, the neutral theory (Hubbell, 2001) and the lottery hypothesis $($ Sale, 1977,1978$)$ proposes that species are ecologically equivalent, and thus local community dynamics are the result of stochastic changes in birth, death, emigration and immigration rates (i.e. ecological drift). The relative importance of these processes may be reinforced by the potential of species to colonize a local site (i.e. dispersal; Vellend et al., 2014), which may not necessarily be independent of species identity. For instance, in regions where species have low dispersal capacity (Chust et al., 2016), and habitat patches and/or trophic resources are heterogeneously distributed in space and time, fluctuations in local population abundances (i.e. demographic stochasticity) may be high, which in turn may promote local coexistence mechanisms and the accumulation of species across spatial and temporal scales in a metacommunity (Mouquet $\&$ Loreau, 2003). Conversely, high dispersal capacity may result in local assemblages that are more similar to the regional pool (i.e. less turnover across sites), particularly if dominant species possess traits that make them competitively superior (Mayfield \& Levine, 2010) and/or exert strong trophic control on prey populations (Chase et al., 2009).

Advances in the taxonomic coverage and resolution of species trait data and molecular phylogenies, coupled with large-scale data on species geographic distributions, have advanced our understanding of the importance of community assembly mechanisms across spatial environmental gradients (Cadotte et al., 2013). Traits are morphological, physiological or phenological features that influence species' performance (Violle et al., 2007), and therefore, determine species niches (Mcgill et al., 2006). Likewise, based on the assumption that closely related species are ecologically more similar (i.e. phylogenetic niche conservatism, Losos, 2008), patterns of phylogenetic community structure have been widely used to infer assembly mechanisms (e.g. Montaño-Centellas et al., 2019; Webb et al., 
2002). Investigating the amount (i.e. richness) and degree of differentiation (i.e. divergence) in functional traits (functional diversity, FD) and evolutionary histories (phylogenetic diversity, PD) offers invaluable insights on community assembly mechanisms (CavenderBares et al., 2009; Tucker et al., 2017). However, to date, only a few studies have investigated the relative importance of these processes across broad latitudinal gradients (e.g. Kraft et al., 2008; Lamanna et al., 2014), and most fail to integrate information on species relative abundances.

Marine fishes are a highly diverse taxon (> 35,000 species), occupy contrasting environments, have high dispersal capacities, and encompass a wide range of ecological strategies that are key to mediate ecosystem resilience and productivity (Duffy et al., 2016). The recent publication of reconstructed time-calibrated phylogenetic trees for ray-finned fishes (Rabosky et al., 2018), coupled with vast information on ecological trait data (Villéger et al., 2017), makes them an ideal model taxon to test macroecological predictions on the relative importance of deterministic versus neutral processes. At large spatial scales, information on species traits and evolutionary histories have contributed to enhance our knowledge of ecological and historical factors driving TD, FD and PD (e.g. Barneche et al., 2019; Leprieur et al., 2016; McLean et al., 2021). At regional scales, empirical studies have provided insights on the relative importance of niche (Pecuchet et al., 2016) and neutral processes (Hubert et al., 2011) in driving assemblage structure in both temperate and tropical ecosystems. However, most empirical analyses of these processes have focused on high diversity systems (Indo-Pacific Ocean; e.g. Ford \& Roberts, 2019), raising questions of whether ecological mechanisms that have contributed to LDG in species-rich ocean basins can be generalized across species-poor regions (e.g. Atlantic and Pacific Oceans).

Here, we fill this knowledge gap by compiling abundance, trait and phylogenetic information on shallow-water $(<30 \mathrm{~m})$, reefassociated, ray-finned fishes from 851 standardized underwater visual census transects across 279 sites (i.e. reefs) in the eastern Atlantic Ocean, from the equator $\left(0^{\circ} \mathrm{N}\right.$ of latitude) to near the Arctic Circle ( $60^{\circ} \mathrm{N}$ of latitude). This ocean basin has a deep history of isolation from the marine biodiversity hotspot in the Indo-Pacific, being subjected to intense glaciation periods during the Quaternary (2.6 Ma to present), resulting in an impoverished reef fish fauna with remarkable levels of regional endemism (Almada et al., 2013; Floeter et al., 2008). To date, studies on the biogeographical and environmental constraints that have shaped the functional and phylogenetic structure of reef fish faunas in this basin have been restricted to tropical regions (Bender et al., 2013, 2017), or constrained to single traits (e.g. Beukhof et al., 2019). We used a unified framework based on generalizations of hill numbers (Chao et al., 2014), to quantify the local (alpha) TD, FD and PD of eastern Atlantic Ocean reef fishes, whilst varying the sensitivity of the metrics to species relative abundances. By comparing observed values of FD and PD to those expected under a null model (Ulrich \& Gotelli, 2013), we tested macroecological predictions on the relative importance of assembly rules, and explore the putative drivers of the patterns (temperature, productivity, area, geographic isolation, depth and human population). Specifically, we formulated the following questions:

1. Are FD and PD lower than sampling expectation (i.e. clustered) at higher latitudes due to energetic and resource constraints?

2. Are FD and PD higher than sampling expectation (i.e. overdispersed) in the tropics as a result of resource and energy availability, stronger historical competition and more stable climates leading to higher niche partitioning?

3. Do FD and PD decline with latitude at the same rate that would be expected from sampling expectation (i.e. randomness)?

4. Do demographic stochasticity vary consistently with latitude independently of species functional identity?

\section{2 | MATERIALS AND METHODS}

\section{1 | Survey data}

We compiled abundance data for reef fishes from two independent data sources: the Reef Life Survey Program (RLS; Edgar et al., 2020) and a comprehensive data synthesis from a collaborative network of researchers in the eastern Atlantic Ocean (Supporting Data). Survey sites consisted of shallow $(9.4 \pm 4.9 \mathrm{~m}$, mean $\pm \mathrm{SD})$ rocky reefs, separated by at least $1 \mathrm{~km}$ to minimize non-independence of fish counts. A total of 279 sites, spread through six biogeographic regions, were surveyed: Gulf of Guinea Islands, Cabo Verde, Webbnesia, South European Atlantic Shelf, Celtic Sea, and North Sea (Freitas et al., 2019; Spalding et al., 2007; Figure 1). All surveys were conducted during daylight hours ( 9 am to 5 pm) throughout 2010 to 2018. Where multiple years were available for a single site, we retained the most recent survey (mean $2013 \pm 2$ SD).

Fish counts were performed using standard underwater visual census belt-transects, although slight differences in transect dimension existed depending on the data source. The RLS program uses trained, volunteer, SCUBA divers to perform counts of fishes along a fixed transect ( $50 \mathrm{~m}$ length $\times 10 \mathrm{~m}$ width; $500 \mathrm{~m}^{2}$; Edgar et al., 2020). In the eastern Atlantic dataset, all transects were $25 \mathrm{~m}$ length $\times 4 \mathrm{~m}$ width $\left(100 \mathrm{~m}^{2}\right)$. A small subset of the data, in the Celtic Sea $(30 \mathrm{~m}$ length $\times 4 \mathrm{~m}$ width; $\left.120 \mathrm{~m}^{2}\right)$ and Cabo Verde $(20 \mathrm{~m}$ length $\times 2 \mathrm{~m}$ width; $40 \mathrm{~m}^{2}$ ), used a different area (Supporting Data). To minimize the potential bias introduced by varying transect dimensions, we excluded non-sedentary fish families with anti-diver behaviour and very patchy distributions (e.g. sharks and rays, and families Carangidae and Scombridae; Kulbicki et al., 2010). We also excluded small-bodied pelagic schooling species (families Clupeidae and Atherinidae) and small $(<5 \mathrm{~cm})$ cryptobenthic species (e.g. families Gobiidae, Blenniidae), as these fishes were not consistently sampled. Fishes were identified to the species level, although a small proportion ( $8.5 \%$ of the total) were identified to a higher taxonomic level (minimum at the family level). Our analyses comprised conspicuous reef fish families, for a total of 188,881 individual fish belonging to 162 species within 94 genera, 48 families and 14 orders (Appendix S1, Table A1). 


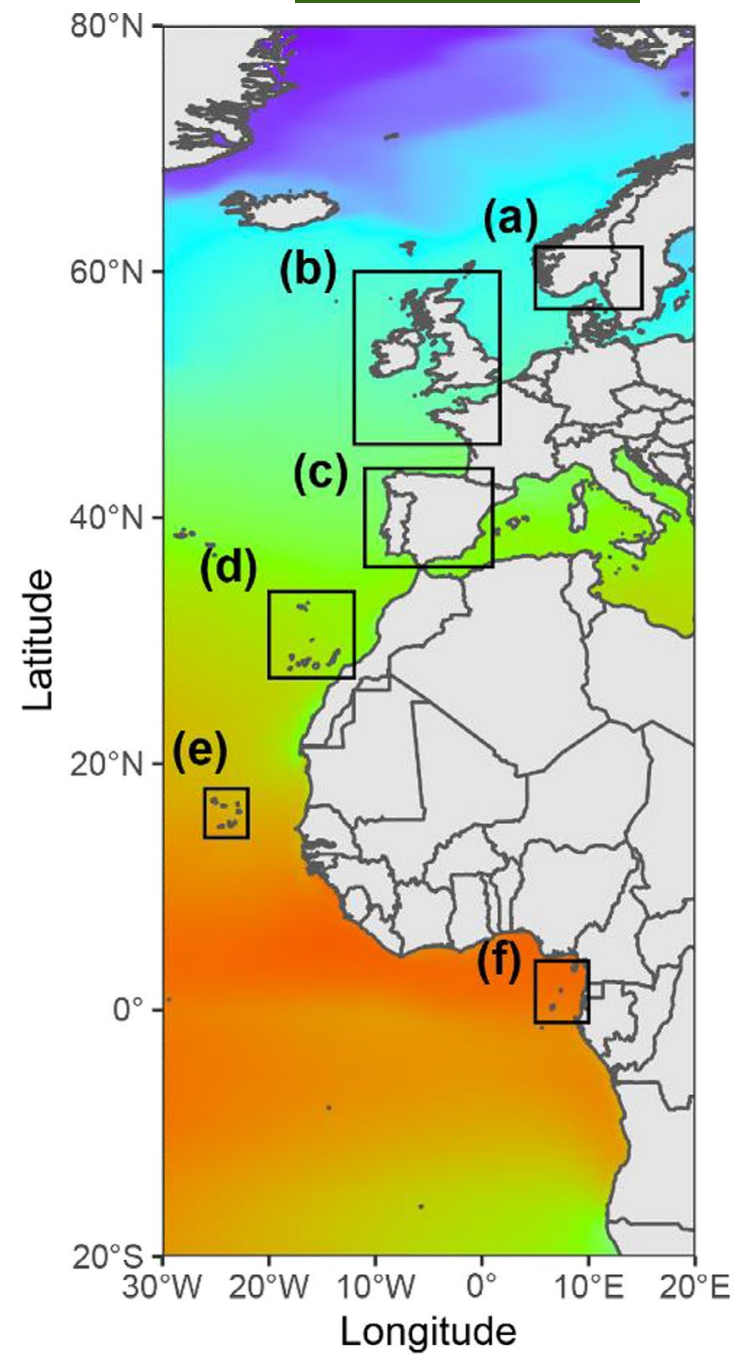

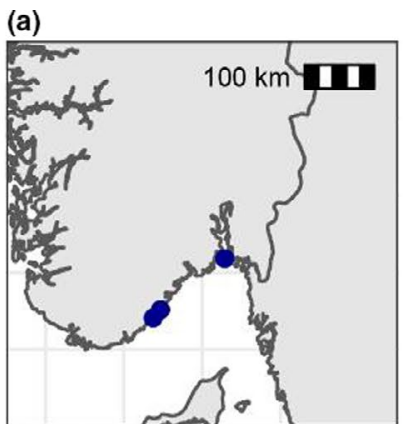

(c)

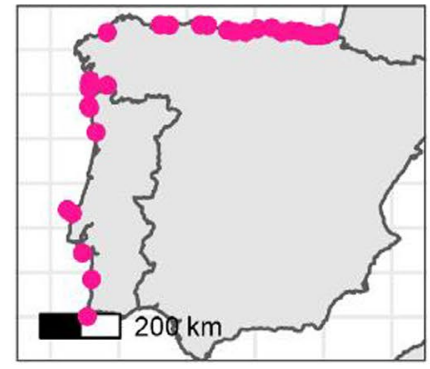

(e)

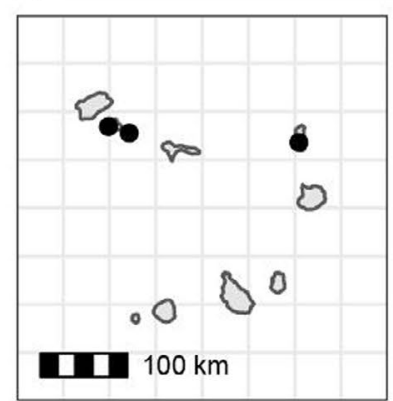

(b)

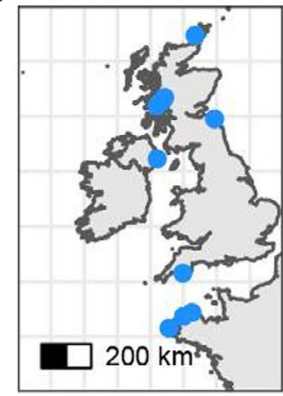

(d)

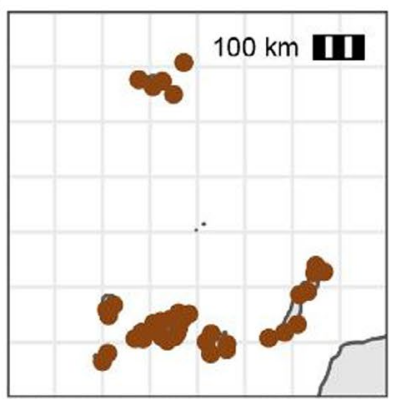

(f)

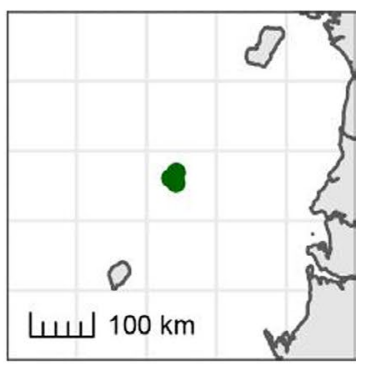

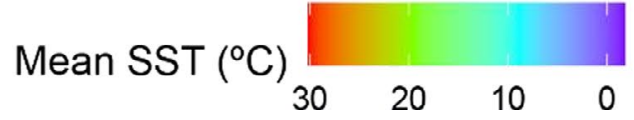

FIGURE 1 Map of eastern Atlantic ocean ecoregions, including survey sites where census of reef-associated fishes were conducted: (a) North Sea (17 sites; $n=67$ transects), (b) Celtic Sea (18 sites; $n=64$ transects), (c) South European Atlantic Shelf (75 sites; $n=228$ transects), (d) Webbnesia (117 sites; $n=282$ transects), (e) Cabo Verde (34 sites; $n=166$ transects), and (f) Gulf of Guinea Islands (18 sites; $n=44$ transects). Satellite measures of mean ocean sea surface temperature (SST) are overlaid in the map. Coloured dots within panels indicate groups of sites within a 12-km distance. Maps and points are projected on WGS84

\section{2 | Trait and phylogenetic data}

We selected a set of five functional traits to capture variations in the ecological roles of eastern Atlantic reef fishes. Traits selected represent key attributes of species that are linked to species life history strategies, behaviour, trophic ecology and habitat utilization (Stuart-Smith et al., 2013): maximum length, trophic guild, water column position, habitat and gregariousness (Appendix S1, Table A2). These traits are known proxies for ecosystem functions and have been consistently used in previous biogeographical analyses of reef fish FD (Mouillot et al., 2014). Trait values were mainly obtained from Fishbase (Froese \& Pauly, 2012), and were cross-checked with the published literature and the authors knowledge of the species.
Species with missing trait information ( $5 \%)$ were assigned trait values from a conspecific, often within the same genus and geographic area. Records of species that were not identified to the species level $(\sim 8 \%)$ were assigned an averaged value of the same genus (or family). Since all traits were categorical, species were grouped into functional entities, that is, groups of species with unique combinations of trait values.

The all-taxon assembled phylogenetic tree was sourced from time-calibrated phylogenies in the ray-finned fish tree of life (https:// fishtreeoflife.org/), downloaded as nexus format using the 'fishtree' 0.3.2 R package (Chang et al., 2019). A total of 21 species (12\% of the total) were missing in the phylogenetic tree, mainly species not identified to the species level. These species had a low contribution 
to the overall abundance ( $2.7 \%$ of the total), and there were no systematic biases in their geographic location; therefore, we excluded them from the analyses. We assessed the extent to which phylogenetic distances were good proxies of ecological similarities (i.e. "phylogenetic signal", Losos, 2008), as specified by the traits considered, by running a mantel test (via Pearson correlation, through 999 permutations) between the cophenetic distance matrix and the gower dissimilarity matrix. There was a connection between both matrices ( $p=0.001)$, although the moderate correlation coefficient $(r=0.35)$ indicated the presence of both conserve and labile traits.

\section{3 | Diversity indices}

We used a unified framework based on generalizations of Hill numbers to measure TD, FD and PD of local (alpha-diversity) eastern Atlantic reef fish assemblages (Chao et al., 2014). All metrics were calculated at the site scale, with transect-level species abundances pooled (summed). Hill numbers provide a parametric family of diversity indices, differing by a parameter " $q$ " that determines their sensitivity to species relative abundances: " $q$ " $=0$ (species composition only), " $q$ " = 1 (more weight on common species) and " $q$ " = =2 (more weight on dominant species). For FD and PD, the metric measures the effective number of phylogenetic and functional entities in an assemblage, which are defined by a time $T$ parameter (i.e. time since divergence) in a phylogenetic tree for PD, and by a threshold level of trait dissimilarity $\tau$ between any two species for FD (Chao et al., 2019). Species within the specified threshold value are functionally and phylogenetically equally distinct (i.e. belong to the same functional or phylogenetic entity). Within this framework, changes in the "q" parameter not only influence the sensitivity of the metric to abundance information, but also the diversity dimension being measured (Tucker et al., 2017). For " $q$ " $=0$, the metric aligns with a richness (i.e. how much; e.g. Faith's PD index and Functional Attribute Diversity) dimension. For " $q$ " $>0$, the metric aligns more closely with a divergence dimension (i.e. how different; e.g. Mean Pairwise Distance and Rao's quadratic entropy). We defined $T$ as the mean branch length in the phylogenetic tree (Chao et al., 2014), whilst $\tau$ is defined as the average of all Gower distances between FEs present in the global species pool (Chao et al., 2019). We chose a Gower dissimilarity matrix to represent functional distances, as this allows mixing different types of variables, whilst giving them equal weight. All indices were calculated in R (R Core Team, 2019) via the 'hillR' 0.4.1 package ( $\mathrm{Li}$, 2018) and R code at https://github.com/AnneChao/FunD.

\subsection{Null models}

Numerical dependencies between species richness and FD and PD limits their ability to make inferences about the relative importance of assembly rules. To overcome this limitation, we used a null model approach, in which species identities were reshuffled randomly from a regional pool of species, maintaining species occurrence frequency and sample species richness (Gotelli, 2000). We defined the regional pool as all the species observed in the surveys within the eastern Atlantic Ocean, as we were interested in testing how large-scale variation in abiotic and biotic factors shape patterns of species occurrences and abundances (Lamanna et al., 2014). We iterated this randomization 999 times and subsequently computed a standardized effect size (SES), by estimating the divergence between observed diversity and the average diversity of the null model, divided by the standard deviation in the null communities; SES = (obs - mean (null))/sd(null) (Ulrich \& Gotelli, 2013; Figure A1). This was done for FD and PD, under each " $q$ " parameter, to test whether the detection of assembly rules was influenced by the relative weight on species relative abundances, as well as the diversity dimension being measured (i.e. richness vs. divergence components; Münkemüller et al., 2020). Our SES metrics were unaffected by the addition of species for FD, whilst they were only weakly affected for PD under " $q$ " $=0$ and " $q$ " = 1 (Figure A2). Following Pecuchet et al. (2016), we classified assemblages within the interquartile range of the null distribution as being purely random, whilst assemblages below or above the 25th and 75th percentiles, respectively, were considered as being predominantly overdispersed (i.e. higher than sampling expectation) or clustered (i.e. lower than sampling expectation). Assemblages that differed significantly (i.e. outside the 95th range) from the null model were considered as being purely overdispersed or clustered. Null models were created in R using an independent swap algorithm in the 'picante' 1.8 package (Kembel et al., 2010).

\subsection{Drivers of the LDG}

We compiled a set of 20 explanatory covariates capturing biophysical and biogeographical drivers receiving empirical support in previous macroecological analyses of reef fish diversity. These included: temperature (Edgar et al., 2017; Tittensor et al., 2010), productivity (Stuart-Smith et al., 2013), habitat area (Barneche et al., 2019) and geographic isolation (Bender et al., 2017; Appendix S2, Table A3). Temperature and productivity were sourced from the Bio-ORACLE database (Tyberghein et al., 2012), which included satellite-derived monthly climatologies from Aqua-MODIS (sea surface temperature [SST], ${ }^{\circ} \mathrm{C}$ ) and model-interpolated values of nitrate (NO3, $\mu \mathrm{mol} / \mathrm{L}$ ) and phosphate (PO4, $\mu \mathrm{mol} / \mathrm{L})$, respectively. We additionally sourced values of net primary productivity (NPP, $\mathrm{mgC} / \mathrm{m}^{2}$ day) from the marine socio-environmental covariates database (Yeager, Marchand, et al., 2017). Several climatological metrics were initially considered: mean, minimum, maximum and range; due to collinearity issues $(r>0.8)$, we retained the mean for consistency with previous large-scale studies. Habitat area and geographic isolation were represented by extracting map-derived variables from a global bathymetric grid, sourced from the MARSPEC database (Sbrocco \& Barber, 2013), including: continental shelf area, number of adjacent ecoregions, distance to the nearest continental mass and geographic connectivity to shallow water $(<30 \mathrm{~m}$ ) habitats (Appendix S2, Table A3). Detailed explanations on how the covariates were sourced and 
computed, including spatial and temporal scales, are provided in the supporting information (Appendix S2, Table A3).

In addition to these macroecological drivers, we included two local scale predictors that might contribute to explain local deviations in TD, SES FD and SES PD: human population (i.e., sum of population density values around a 50-km buffer from the LandScan 2011 population density grid) and depth (i.e. average depth of transects at each site; Appendix S2, Table A3). Predictor variables with skewed distributions were $\log (x+1)$ or square-root transformed. We tested for collinearity and variance inflation factors (VIF) in the covariates, which resulted in the selection of six predictors (SST, Nitrate, NPP, Human population, Geographic isolation, and Depth) with VIF $<5$, indicating multicollinearity was not a concern (Figure A3). All continuous covariates were standardized (mean $0 \pm 1$ SD) prior to analyses to account for differences in scaling.

\section{6 | Statistical modelling}

Prior to analyses, TD, SES FD and SES PD estimates were corrected for local variations in the survey effort (i.e. total area sampled per site). First, we ran a linear regression between each local diversity estimate and the total number of individuals sampled at a site. Then, we extracted the residuals of each linear regression, which were used as a new metric that corrected for total fish abundance (Appendix S1, Figure A4). For these analyses, TD indices and site abundances were a priori $\log (x+1)$ transformed to improve normality.

We tested for latitudinal variation in TD, SES FD and SES PD of eastern Atlantic reef fishes. Models were developed using general additive models (GAMs), fitted using cubic regression splines via the 'mgcv' 1.8.31 R package (Wood, 2006). The basis dimensions " $k$ " of the smoothers were limited to five, to avoid overfitting and ensure monotonic relationships. Comparison of modelled curves under varying " $q$ " parameters provide information on the degree of evenness in an assemblage (Chao et al., 2014), as well as potentially signalling the role of demographic stochasticity in community assembly (Vellend, 2010; Vellend et al., 2014). High reductions in attribute values under increasing " $q$ " depicts highly uneven assemblages, and/or high variance in species abundances across sites within a metacommunity (here ecoregions). Additionally, we compared the relative contribution (\%) of overdispersion, clustering and randomness to the assembly of reef fish assemblages across ecoregions, each depicting a latitudinal midpoint.

The influence of covariates on TD, SES FD and SES PD of eastern Atlantic reef fishes was determined using linear models, for each " $q$ " parameter and biodiversity dimension, via the 'stats' 3.6.2 $\mathrm{R}$ package (Bates et al., 2014). Model selection was carried out in the 'MuMIn' 1.43.17 R package (Barton, 2018), by fitting models with all possible combinations of predictor variables up to four to avoid overfitting, and comparing models based on the Akaike Information Criterion corrected for small sample sizes (AIC ${ }_{c}$ ). A null model containing the intercept was also included in the model set. When competing models had comparable levels of support (within two units of the lowest AIC model), we selected the most parsimonious (i.e. fewer parameters; Burnham \& Anderson, 2003). The absolute importance of explanatory covariates was then inferred from model-averaged conditional regression coefficients (Galipaud et al., 2017).

Finally, we investigated whether demographic stochasticity varied across latitude. First, we computed the mean and variance (SD) in the abundance of each species across sites within each ecoregion (i.e. metacommunity; Appendix S1, Figure A5). Then, the variance of species abundances was regressed against latitude using GAMs to capture potential nonlinearities, following identical criteria as specified above. GAMs were run independently for each major trophic guild in the dataset (i.e. planktivores, benthic invertivores, higher carnivores, omnivores and herbivores/detritivores). This enabled us to test whether there are deterministic factors that shape the extent of demographic stochasticity along latitudinal gradients. We accounted for the potential role of species dispersal potential in either increasing or decreasing demographic stochasticity by including the species-specific body size (maximum length from fishbase) as a covariate in the models. Latitude and body-size had correlations coefficients $<0.5$ for any trophic guild, indicating no collinearity issues when including them in the same model.

All models were visually inspected for residual patterns, and we assessed the presence of spatial autocorrelation via semivariograms plots using the 'gstat' 2.0.4 R package (Pebesma, 2004) and global Moran's I test (with $p$-values estimated via 999 Monte Carlo simulations) through the 'ape' 5.3 R package (Paradis \& Schliep, 2019). Semivariogram plots indicated the presence of weak, positive, spatial autocorrelation in the residuals of TD, SES FD and SES PD, generally within distances of 10-20 km (Appendix S1, Figures A6 and A7). This indicates the presence of other local factors not accounted for in the model, that are unlikely to have biased the macroecological patterns reported here (Diniz-Filho et al., 2003).

\section{3 | RESULTS}

\section{1 | Latitudinal diversity gradients}

The TD of eastern Atlantic reef fishes consistently declined with latitude, peaking at $\sim 15^{\circ}-20^{\circ} \mathrm{N}$, and displaying a second mode (of lower magnitude) at $\sim 45^{\circ} \mathrm{N}$ (Figure 2a). The modelled curves diverge at low-latitude $\left(<20^{\circ} \mathrm{N}\right)$ regions, when increasing the weight on common ( $q$ " $=1$ ) and dominant ( $q$ " $=2$ ) species, indicating high unevenness in the local assemblages and/or high demographic stochasticity. Latitude was a good predictor of the spatial patterns in TD, explaining ca. $40 \%$ of the variance in species richness (TD ${ }^{\prime \prime}=0$ ), with the goodness of fit of the model consistently declining when increasing the weight on common (" $q$ " = 1, ca. 33\% explained variance) and dominant (" $q$ " $=2$, ca. $26 \%$ explained variance) species (Appendix S2, Table A4).

After controlling for the effect of species richness on FD and PD, we found that SES FD and SES PD varied significantly across latitude, independently of the weight on species relative 


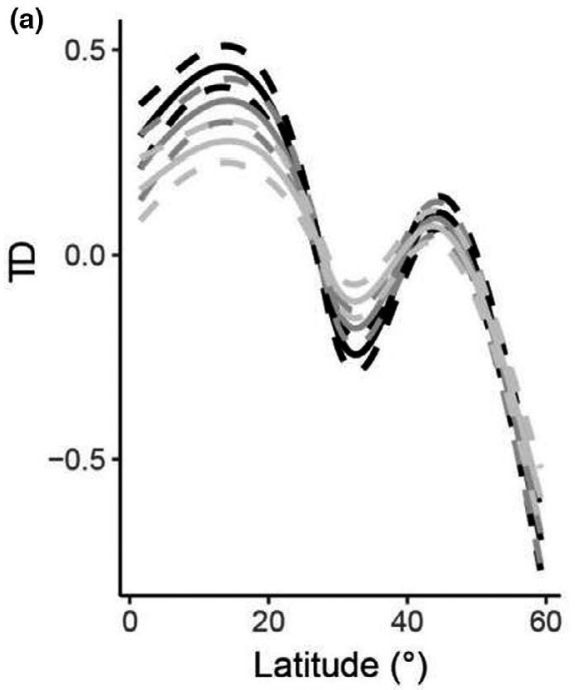

(b)

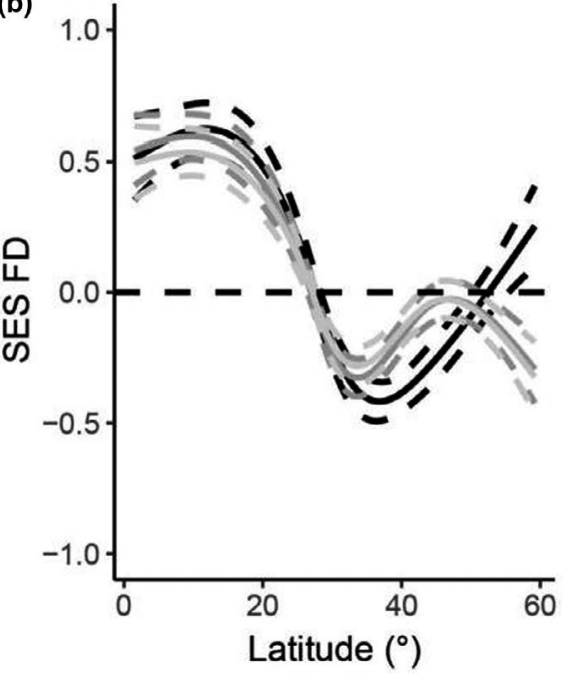

(c)

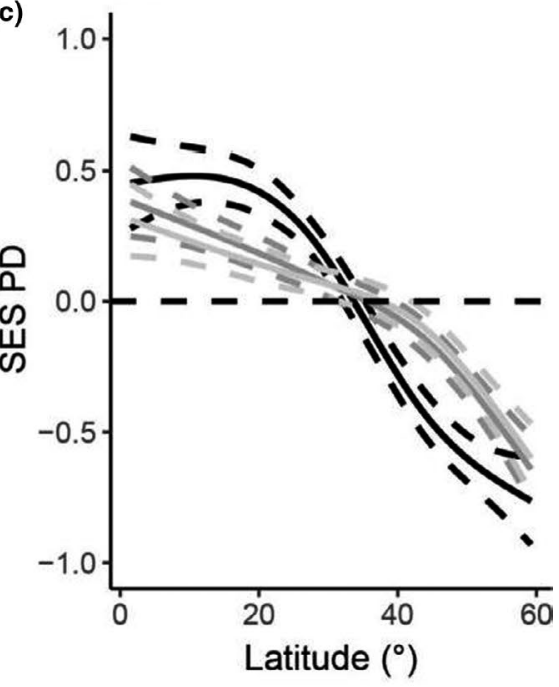

$q=2$

FIGURE 2 Predicted relationships between latitude $\left(^{\circ}\right)$ and (a) taxonomic (TD), (b) standardized effect size functional diversity (SES FD), and (c) SES phylogenetic diversity (SES PD) of eastern Atlantic reef fishes, under varying " $q$ " parameters: " $q$ " $=0$ (black, species compositions only), " $q$ " = 1 (dark grey, higher weight on common species) and " $q$ " = 2 (light grey, higher weight on dominant species). Solid lines are mean fitted values from general additive models, and dashed lines are $95 \% \mathrm{Cl}$. Note: $y$-axis depicts the metric value after correcting for total fish abundance at sites (see Appendix S1, Figure A4)

abundances, and therefore the dimension measured (richness, $" q "=0$ vs. divergence, " $q "=1$ and " $q "=2$; Appendix S2, Table A4). At low latitude, FD was higher than sampling expectation (i.e. overdispersed), with SES FD peaking at approximately the same latitude as TD $\left(\sim 15^{\circ}-20^{\circ} \mathrm{N}\right.$; Figure $\left.2 \mathrm{~b}\right)$. Values of SES FD progressively declined with increasing latitude, gradually shifting from overdispersion to clustering (i.e. lower than sampling expectation); this pattern was disrupted at high latitude $\left(>45^{\circ} \mathrm{N}\right)$, where modelled curves became closer to random expectation. Latitude alone explained $\sim 15 \%$ of the variance in SES FD values, irrespective of the " $q$ " parameter (Appendix S2, Table A4). The SES PD steadily declined with latitude, from overdispersed to clustered assemblages (Figure 2c). The magnitude of overdispersion and clustering was stronger for the richness dimension (" $q$ " $=0$ ), with latitude explaining ca. $20 \%$ of the variance (Appendix S2, Table A4). Increasing the sensitivity on species relative abundances resulted in the pattern becoming closer to random expectation, with the variance explained by latitude decreasing when increasing the weight on common (" $q$ " =1, ca. $13 \%$ explained variance) and dominant ( $q$ " $=2$, ca. $9 \%$ explained variance) phylogenetic entities.

\section{2 | Contribution of overdispersion, clustering and randomness}

The relative contribution of overdispersion and clustering to the assembly of eastern Atlantic reef fishes shifted predictably with latitude, from a higher proportion of overdispersed assemblages at low-latitude ecoregions, to increasingly higher proportion of clustered assemblages at high-latitude ecoregions. However, a substantial proportion of assemblages were not different from random expectation in all the ecoregions investigates, and the majority of overdispersed and clustered assemblages were within the interquartile range (i.e. not statistically different from the null model). Increasing the sensitivity of SES FD and SES PD to relative abundances (" $q$ " > 0, Figure 3b,c,e,f) generally resulted in a larger proportion of assemblages displaying no deviation from random expectation. Importantly, SES FD and SES PD displayed similar patterns, although the latter failed to detect patterns of overdispersion that significantly (> 95th) differed from the null model.

\section{3 | Influence of environmental, geographical and local-scale drivers}

The taxonomic richness (TD" $q$ " $=0$ ) of eastern Atlantic reef fishes was best predicted by a model containing the effect of SST, geographic isolation and NPP (Table 1). This model received large support $\left(\omega \mathrm{AIC}_{\mathrm{c}}=0.67\right)$ and explained ca. $32 \%$ of the variance. Increasing the weight on common (" $q$ " $=1$ ) and dominant (" $q$ " = 2) species resulted in the inclusion of human population within the top-ranked models, and a consistent decline in the variance explained by the models (ca. $24 \%$ and ca. $19 \%$ for " $q$ " = 1 and " $q$ " = 2, respectively). SST was the strongest predictor irrespective of the " $q$ " parameter, followed by NPP and geographic isolation (Figure 4a). These predictors had a positive effect on TD, but the absolute importance declined under increasing " $q$ " parameters, except for SST that remained invariant (Figure 4a). 


$$
\text { "q" = } 0
$$

(a)

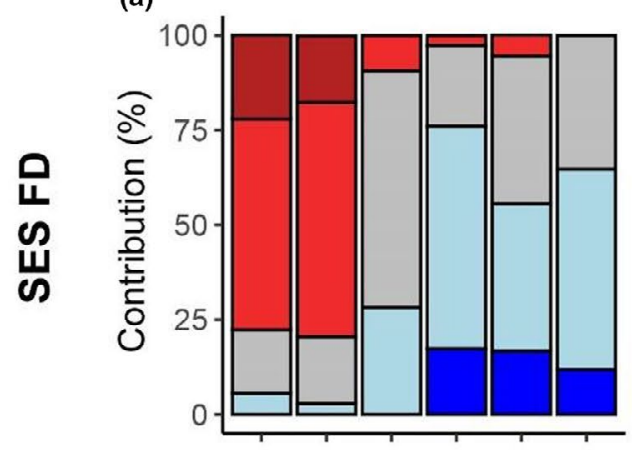

(d)

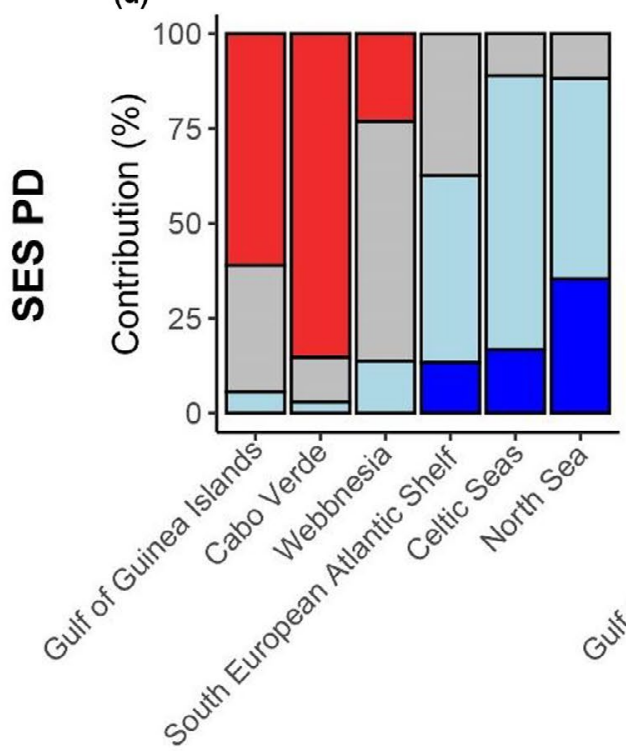

$$
\text { "q" = } 1
$$

(b)

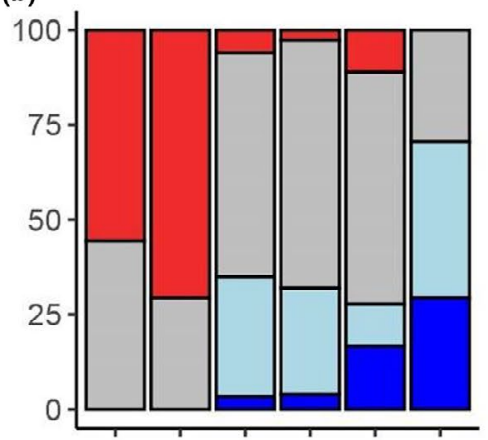

(e)

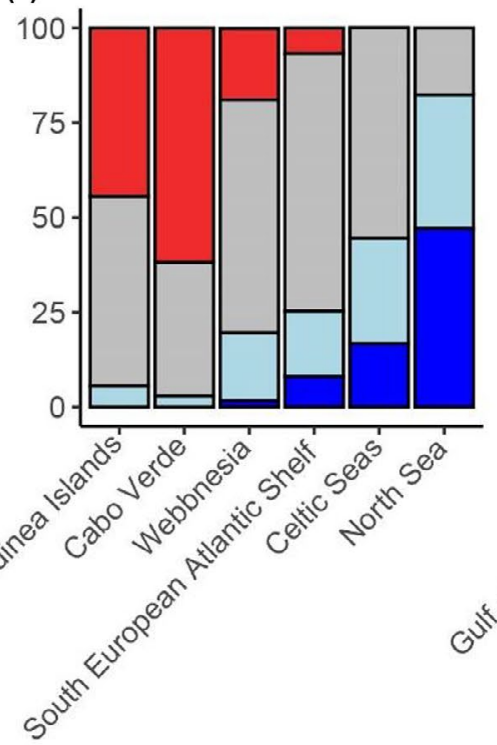

(c)

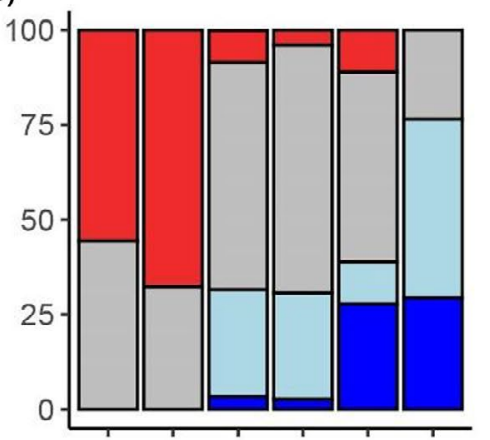

(f)

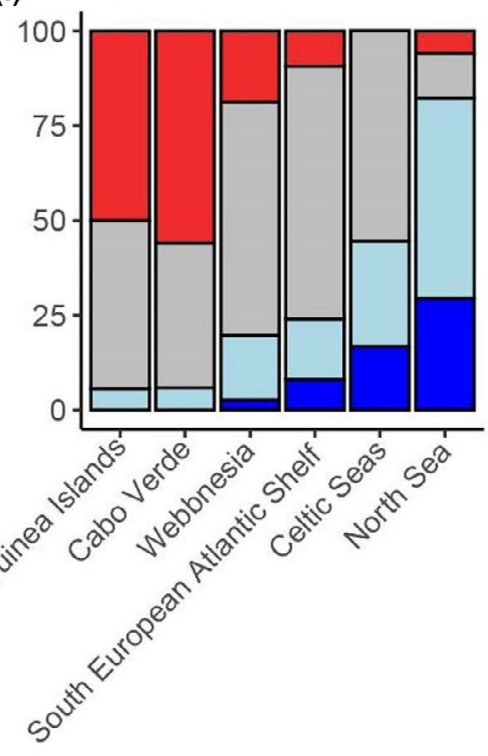

$0^{\circ}$

Latitude

Overdispersed $\left(95^{\text {th }}\right)$

Overdispersed $\left(75^{\text {th }}\right)$

Random

Clustered $\left(75^{\text {th }}\right)$

Clustered $\left(95^{\text {th }}\right)$

FIGURE 3 Relative contribution of overdispersion (red), clustering (blue) and randomness (grey) to the assembly of eastern Atlantic reef fishes across ecoregions (ordered in increasing latitude, from left to right). In both standardized effect size functional diversity (SES FD) and SES phylogenetic diversity (SES PD), patterns were investigated under increasing sensitivity to species' relative abundances: (a, d) " $q$ " $=0$ (species compositions only), (b, e) " $q$ " = 1 (higher weight on common species) and (c, f) " $q$ " = 2 (higher weight on dominant species). Dark red (overdispersed) and blue (clustered) colours depict assemblages that were significantly different from the null model (outside the 95th range)

The SES FD of eastern Atlantic reef fishes displayed a weak association with the set of predictors considered, with the top-ranked models explaining $7 \%$ of the variance irrespective of the weight on functional entities relative abundances (i.e. " $q$ " parameter; Table 1). As in TD, the relative support of the models declined under increasing " $q$ " $\left(\omega \mathrm{AIC}_{\mathrm{c}}=0.35,0.20\right.$ and 0.21 for " $q$ " $=0$, " $q$ " $=1$, and " $q$ " $=2$ respectively). The richness dimension (SES FD" $"$ " $=0$ ) was best predicted by a model containing the effect of geographic isolation, NPP and human population. Geographic isolation had the strongest association with SES FD" $q "=0$, with increasing isolation from the continent having a positive effect on SES values (i.e. greater overdispersion; Figure 4b). NPP also had a positive association with SES FD" " $"$ " $=0$, but its effect was comparatively smaller. In contrast, increased human population was associated with lower SES FD" ${ }^{\prime \prime}=0$ (i.e. higher clustering). The divergence dimension (SES FD" $q^{\prime \prime}=1,2$ ) was best predicted by a model containing the effect of SST, nitrate and depth; however, the effect of the nitrate and depth was relatively weak, with standard errors close to the null expectation (Figure 4b). SST had a positive effect on SES FD" $q$ " $=1,2$, suggesting higher overdispersion was associated with warmer environments. 
TAB LE 1 Best (most parsimonious within two units of the lowest AIC ) linear models predicting variation in taxonomic (TD), standardized effect sizes functional (SES FD) and SES phylogenetic (SES PD) diversity of eastern Atlantic reef fishes, under varying " $q$ " parameters: " $q$ " = 0 (species compositions only), " $q$ " = 1 (higher weight on common species) and " $q$ " = 2 (higher weight on dominant species). The degrees of freedom (df), Akaike weights $(\omega \mathrm{AIC})$ and goodness-of-fit $\left(R^{2}\right)$ are provided for model comparisons

\begin{tabular}{|c|c|c|c|c|c|}
\hline Diversity & "q" & Best models & df & $\omega \mathrm{AlC}_{\mathrm{c}}$ & $R^{2}$ \\
\hline TD & $" q "=1$ & $\mathrm{SST}+$ Geographic isolation $+\mathrm{NPP}+\mathrm{Human}$ population & 6 & 1.00 & 0.24 \\
\hline \multirow[t]{2}{*}{ SES FD } & $" q "=0$ & Geographic isolation+NPP+Human population & 5 & 0.35 & 0.07 \\
\hline & $" q "=1$ & SST+Nitrate+Depth & 5 & 0.20 & 0.08 \\
\hline \multirow[t]{3}{*}{ SES PD } & $" q "=0$ & SST+Nitrate+Depth & 5 & 0.44 & 0.20 \\
\hline & $" q "=1$ & SST+Depth+Human population & 5 & 0.20 & 0.12 \\
\hline & $" q "=2$ & SST+Depth+Human population & 5 & 0.26 & 0.09 \\
\hline
\end{tabular}

Abbreviations: NPP, net primary productivity; SST, sea surface temperature.

(a) TD

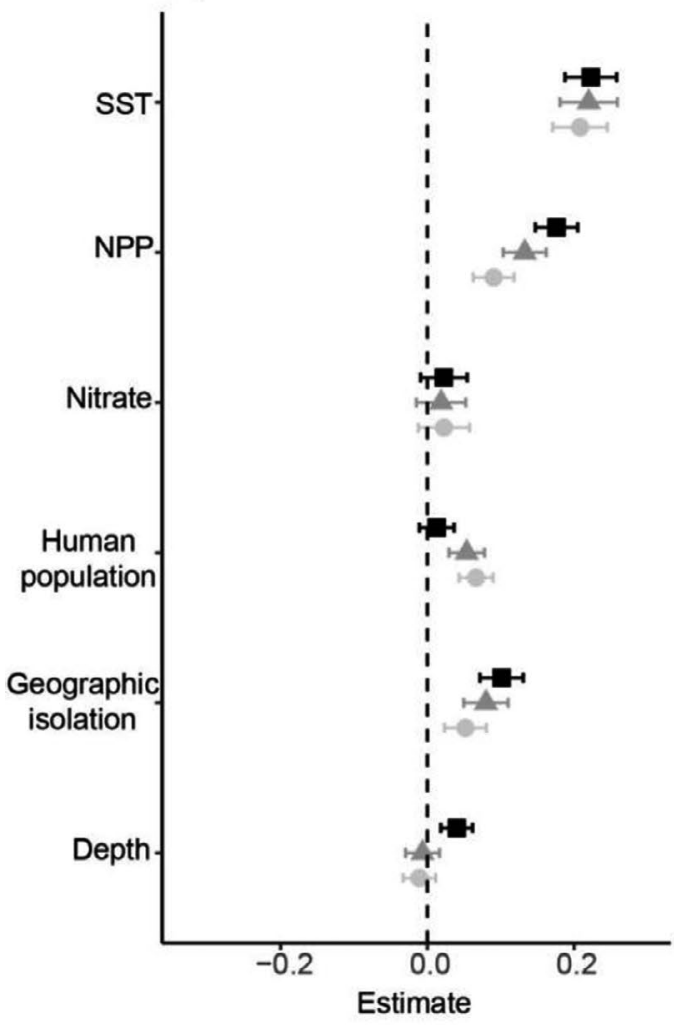

(b)

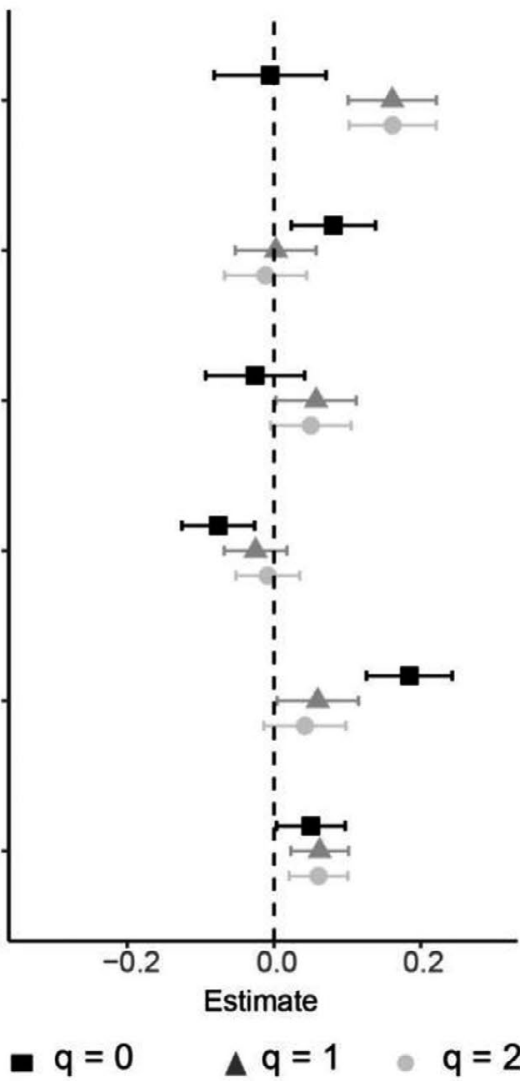

(c) SES PD

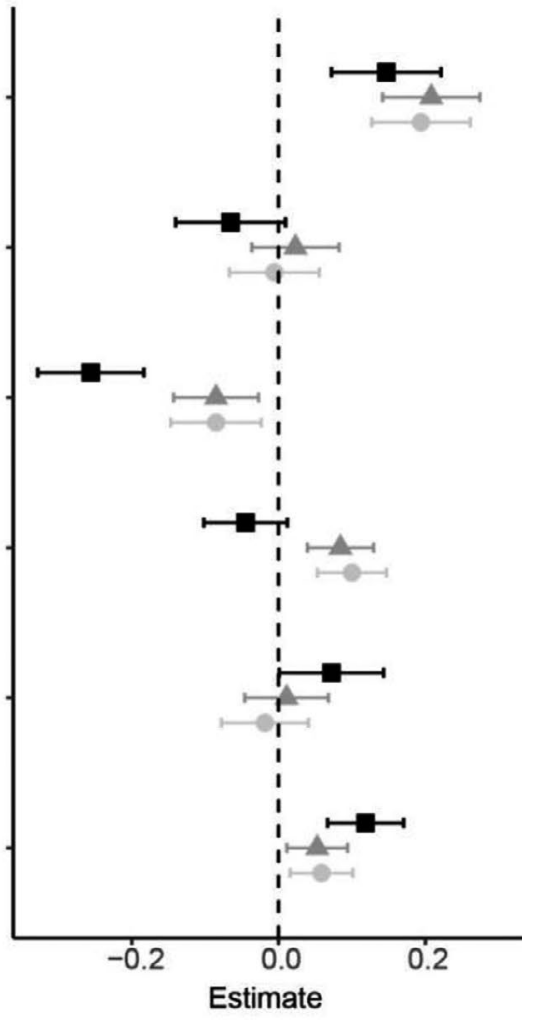

FIGURE 4 Model-averaged coefficients $( \pm$ SE) from linear models testing the effect of explanatory covariates on (a) taxonomic (TD), (b) standardized effect size functional diversity (SES FD), and (c) SES phylogenetic diversity (SES PD) of eastern Atlantic reef fishes, under varying " $q$ " parameters: " $q$ " $=0$ (black, species compositions only), " $q$ " = 1 (dark grey, higher weight on common species), and " $q$ " $=2$ (light grey, higher weight on dominant species). Coefficients depict the partial effect of the predictor, whilst controlling for other covariates, and accounting for the uncertainty of the models

The richness dimension (" $q$ " $=0$ ) of SES PD was best predicted by a model containing the effect of SST, nitrate and depth. This model received moderate levels of support $\left(\omega \mathrm{AIC} c_{c}=0.44\right)$, and explained ca. $20 \%$ of the variance. Nitrate had a strong negative effect on SES PD" $q^{\prime \prime}=0$, with increased concentrations resulting in greater phylogenetic clustering (Figure 4c). In contrast, SST had a positive effect on SES PD" $q^{\prime \prime}=0$, indicating a transition from overdispersed assemblages at warm environments to clustered assemblages at cooler environments. Although weaker in its effect, depth also displayed a positive association with SES PD" $"$ " $=0$, indicating 
higher overdispersion at greater depths. Models for the divergence dimension (SES PD" $q^{\prime \prime}=1,{ }^{2}$ ) had comparatively weaker support $\left(\omega \mathrm{AlC}_{\mathrm{c}}=0.20\right.$, and 026 , for " $q$ " $=1$ and " $q$ " $=2$ respecitvely), and lower explanatory power (ca. $12 \%$ and ca. $9 \%$ explained variance, for $" q "=1$ and " $q$ " = 2, respectively; Table 1). The best model explaining variation in SES PD" $q$ " $=1,2$ contained the effect of SST, depth and human population. These predictors had a positive effect, indicating higher overdispersion at warmer environments, and reefs that were deep and close to large urban centres.

\subsection{Demographic stochasticity}

Demographic stochasticity (i.e. variances of species abundances within an ecoregion) varied significantly across latitude for all trophic guilds investigated, although the pattern was non-significant when accounting for differences in species-specific body size in omnivores and herbivores/detritivores (Appendix S2, Table A5). Planktivores displayed, by far, the strongest variation across sites in their population abundances, with latitude explaining ca. $19.4 \%$ of the variance (Figure 5a). Remarkably, we found that demographic stochasticity for planktivorous fishes peaked at $\sim 15^{\circ}-20^{\circ} \mathrm{N}$, matching the observed peak of diversity for TD, SES FD and SES PD (Figure 5a). Benthic invertivores displayed a U-shape relationship, peaking at low $\left(0^{\circ} \mathrm{N}\right)$ and high $\left(60^{\circ} \mathrm{N}\right)$ latitude regions, with latitude explaining ca. $13.1 \%$ of the variance (Figure 5b). Higher carnivores also displayed a $\mathrm{U}$ shape relationship with latitude, which explained ca. $21.1 \%$ of the variance (Figure $5 \mathrm{c}$ ). Interestingly, in this case, demographic stochasticity was maximal at high latitude regions $\left(>45^{\circ} \mathrm{N}\right)$, which was mainly attributed to the high variance in population abundances of the gadids Pollachius virens and P. pollachius (Figure A4c). Body-size had either a strong negative relationship with the variance of species abundances (planktivores and herbivores; Figure 5f,j), or was maximal for small-sized species (benthic invertivores and omnivores; Figure $5 \mathrm{~g}, \mathrm{i})$. However, carnivores departed from this expectation, and maximal variability in species population abundances was found for species in the middle of the size spectrum (Figure $5 \mathrm{~h}$ ).

\section{DISCUSSION}

Our results provide an understanding of the ecological mechanisms that have contributed to the generation and maintenance of LDGs in reef fishes. Using impoverished eastern Atlantic reef fish assemblages, we empirically demonstrated that neutral and deterministic hypothesis of community assembly are non-mutually exclusive. Instead, these can be placed in a continuum (Vellend et al., 2014), depicting a shifting importance from overdispersion at low latitude $\left(<20^{\circ} \mathrm{N}\right.$, tropical) ecoregions to clustering at high latitude $\left(>20^{\circ} \mathrm{N}\right.$, subtropical and temperate) ecoregions. A large proportion of assemblages displayed no deviation from random expectation across all ecoregions investigated, a pattern that was more marked when increasing the weight on species, functional and phylogenetic entities relative abundances, indicating high demographic stochasticity in reef fishes plays an important role in community dynamics (Hubbell, 2001). However, we found that latitudinal variation in demographic stochasticity is contingent on the trophic identity and dispersal capacity of species, providing a novel view of ecological pathways that may boost and/or constrain the accumulation of species across space and time.

The observed peak of TD at $\sim 15^{\circ}-20^{\circ} \mathrm{N}$ matches that reported in recent large-scale empirical analyses in several marine taxa (Chaudhary et al., 2016), including actinopterygian fishes at global scales (Edgar et al., 2017). Recently, Chaudhary et al. (2021) showed that, since the 1970s, this dip in marine biodiversity has become more pronounced, an effect that can be attributed to ocean warming. This was supported in our analyses, where temperature had the strongest effect on TD, independent of the weight on species' relative abundances. Temperature-dependent metabolic processes are known to constrain local abundance and occupancy patterns over ecological time-scales (Edgar et al., 2017; Tittensor et al., 2010), with temperatures at the equator already exceeding the physiological performance thresholds of many reef-associated fishes (Chaudhary et al., 2021). Other factors could also enhance TD at these latitudes, exemplified in the importance of both geographic isolation and NPP. The positive effect of geographic isolation in TD is surprising, as the theory of island biogeography predicts that increasing isolation should result in lowered species richness (MacArthur \& Wilson, 2001). However, this effect is likely confounded in our study by the proximity of sites in the equator (i.e. Gulf of Guinea Islands) to the equatorial west African margin, characterized by high mean annual precipitation and large inputs of turbid riverine waters (Polidoro et al., 2017), which may constrain the availability of shallow biogenic reef habitats. Likewise, the more oceanic location of the Cabo Verde archipelago may entail higher inputs of allochthonous planktonic production (i.e. 'island mass effect'; Gove et al., 2016), which may be more readily available for reef fishes in clear, sediment-free waters (Johansen \& Jones, 2013). Overcoming the logistical challenges of surveying continental masses at these latitudes will help to clarify the relative importance of these mechanisms.

Tropical regions have been climatically more stable in the geological past, which have contributed to narrow environmental tolerances among tropical reef fish lineages (i.e. "tropical niche conservatism", Wiens \& Graham, 2005). In contrast, high latitude regions have been subjected to marked extinction events in response to glacial periods, a phenomenon that has played a strong role during the quaternary in the eastern Atlantic (Floeter et al., 2008). Under these circumstances, PD at high latitude regions should increasingly represent a filtered subset of lineages, which poses traits to colonize these environments and/or adapted lineages that have originated at high latitude regions (e.g. Gadids, Briggs \& Bowen, 2013). Our results support these predictions, with increasing importance of phylogenetic clustering (i.e. 'environmental filtering') at regions $>20^{\circ} \mathrm{N}$ of latitude, an effect that was stronger when considering the amount (i.e. richness) of PD, and that was partly explained by variations in SST. Considering that cold-temperate and polar lineages originate 


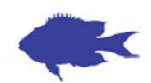

(a) Planktivores

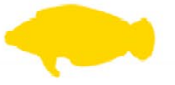

(b) Benthic invertivores

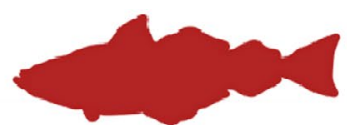

(c) Higher carnivores
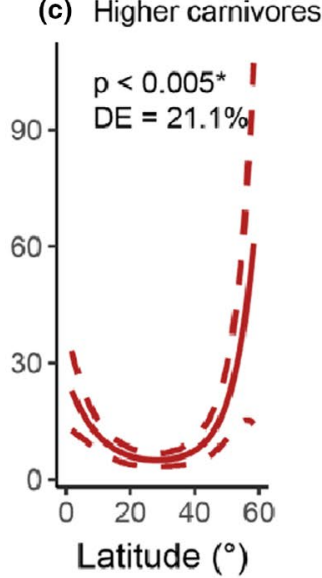

(d) Omnivores

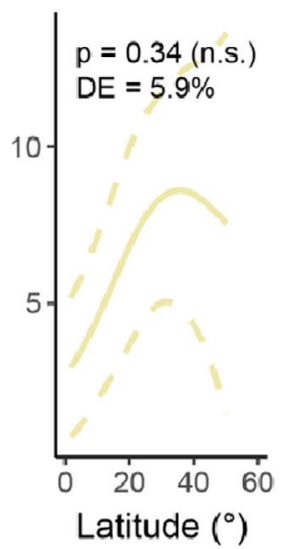

(i)

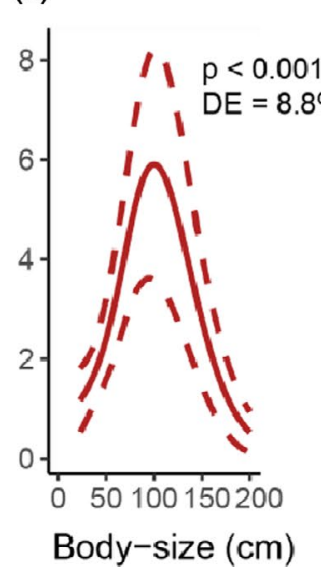

(h)

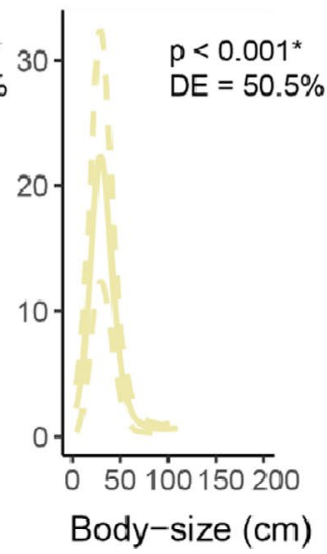

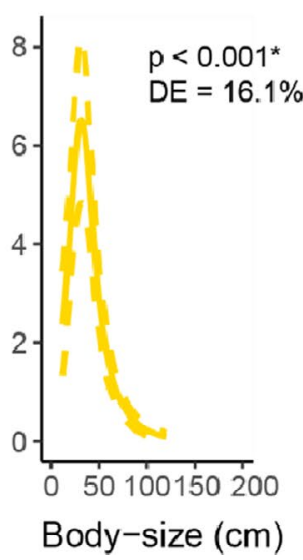

(g)
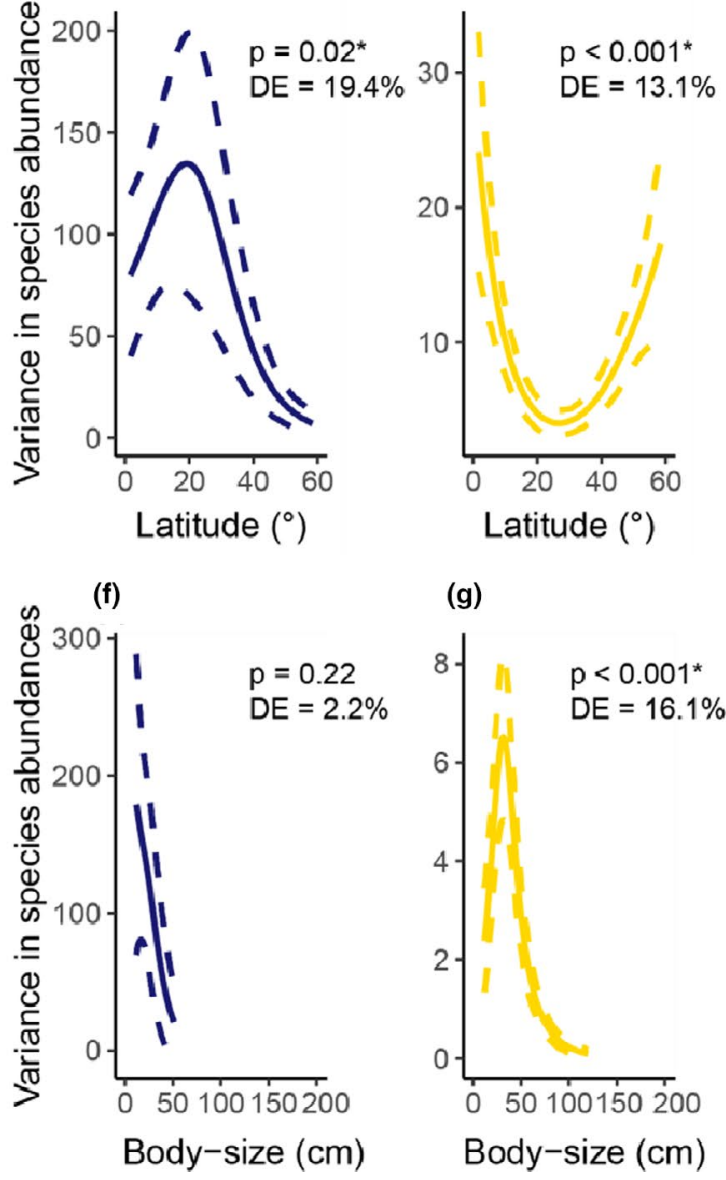

Herbivores/

(e) Detritivores

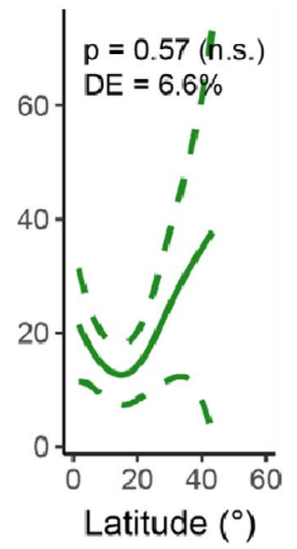

(j)

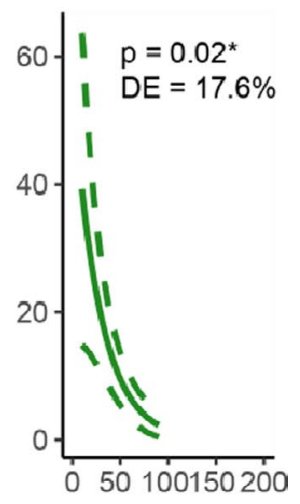

Body-size (cm)

FIGURE 5 Predicted relationships between $(a-e)$ latitude $\left({ }^{\circ}\right)$ and $(f-j)$ body-size, and the variance of species abundances in eastern Atlantic reef fishes, for each trophic guild: (a, f) planktivores (blue), (b, g) benthic invertivores (yellow), (c, h) higher carnivores (red), (d, i) omnivores (light brown) and (e, j) herbivores/detritivores (green). Solid lines are mean fitted values from general additive models, and dashed lines are $95 \% \mathrm{Cl}$. The statistical significance ( $p$-value) and deviance explained (DE) by each term in the model is provided within each panel. Note: Fish shapes depict the family within each trophic guild most contributing to the variance of species abundances across the latitudinal gradient (i.e. not accounting for compositional changes across latitude; see Appendix S1, Figure A5 for species-specific variances within each trophic guild)

at a faster rate than tropical ones (Rabosky et al., 2018), historical and contemporary niche constraints are a plausible agent that culls regional to local levels of diversity at these latitudes. Conversely, topical regions $\left(<20^{\circ} \mathrm{N}\right)$ displayed phylogenetic overdispersion (i.e. 'limiting similarity'), indicating that more stable and warmer climates might have enhanced the diversification of closely related species across more specialized niches (Brown, 2014). This is clearly exemplified in the evolution of tropical herbivorous fishes (Siqueira et al., 2019), which have evolve ecological, morphological or behavioural specializations that enable them to finely partition resources across space and time (Fox \& Bellwood, 2013; Nicholson \& Clements, 2021). Nitrate concentration also had a strong effect on PD, with nutrient enriched waters filtering the amount (i.e. richness) of phylogenetic entities present at site. It is likely that high turbidity (which correlates with nitrates) in areas of large terrestrial run-offs inhibit the feeding performance of many reef-associated lineages (Johansen \& Jones, 2013), with a subset of specialized families supported in these environments.

Functional diversity revealed a more complex pattern underlying the assembly of eastern Atlantic reef fishes, with a weak association with the set of predictors considered. This might result from the coarse environmental predictors included in the models, which do not account for fine-scale habitat features that may correlate with the availability of niche space at the local-scale (Yeager, Deith, et al., 2017). Despite the higher uncertainty in the models, we still detected patterns of functional overdispersion in tropical regions, a result that was partly associated with warmer environments, increased primary productivity and isolation. This reinforces our findings for PD, with lower energetic and resource constraints in the tropics allowing greater partitioning 
of the available niche space (Brown, 2014). Because of the limited functional redundancy of reef fish assemblages in the tropical eastern Atlantic (Mouillot et al., 2014), the increase in FD likely arises as a result of species exploiting unfilled portions of the niche space (i.e. niche expansion driven by ecological opportunities) rather than niche packing (Pellissier et al., 2018). This represents a plausible explanation for the increased overdispersion with geographic isolation, as the Cabo Verde archipelago contains a higher heterogeneity of habitats (Pérez-Ruzafa et al., 2005). Contrary with the expectations, we found an inverted pattern for FD at high latitude $\left(>45^{\circ} \mathrm{N}\right)$ regions, where modelled curves became closer to random expectation. We suggest that this might have arisen through two non-mutually exclusive mechanisms, and might be related to the second mode of TD observed at $\sim 45^{\circ} \mathrm{N}$. Firstly, this corresponds to the latitudinal point at which there is a transition from warm Lusitanian to cool Boreal reef fish assemblages (Almada et al., 2013), which markedly differ in their trait composition and structure (McLean et al., 2018). Second, this might be an imprint of the historical overexploitation of large demersal predatory species (especially from the family Gadidae) in the Celtic Seas and North Sea (Pauly et al., 2002). This have likely contributed to the increased demographic stochasticity of large higher carnivores at these latitudes, increasing spatial heterogeneity in the trophic control exerted by these species and in turn augmenting the turnover (beta-diversity) of co-occurring fish assemblages (Ellingsen et al., 2020).

In Hubbell's neutral theory (Hubbell, 2001) and Sale's lottery hypothesis (Sale, 1978), stochastic fluctuations in species population abundances and immigration from the regional pool irrespective of species identity (i.e. functional equivalence) promotes the coexistence of species with similar habitat and resource requirements. Our results partly support these hypotheses, exemplified in the increased relative importance of 'neutral stochasticity', and higher uncertainty in the models, when increasing the weight on species' relative abundances. However, we found that demographic stochasticity was contingent on the trophic identity and body-size of species, suggesting that deterministic and neutral processes interact to shape community dynamics (Vellend, 2010; Vellend et al., 2014). Smaller-bodied species generally had higher variance in their population abundances within a metacommunity (here, ecoregions), likely as a result of their lower dispersal capacities preventing larvae to reach ecologically optimal sites (Chust et al., 2016). Remarkably, we found that the peak of TD, FD and $\mathrm{PD}$ found at $15^{\circ}-20^{\circ} \mathrm{N}$, closely resembled the peak in demographic stochasticity for small-bodied planktivorous fishes, a result that was independent of variations in species body size. This aligns with the recently observed contribution of small-bodied planktivorous fishes to the bulls-eye pattern of reef fish diversity in the Indo-Australian archipelago (Siqueira et al., 2021). Our results extend this finding to a species-poor ocean basin, and suggest that planktivorous fishes may boost the observed latitudinal peak of reef fish diversity. Planktivorous reef fishes were not only diverse and abundant at these latitudes, but their populations were far more variable than any other trophic guild (Appendix S1, Figure A5). We suggest that high, spatially and temporally variable (Arístegui \& Montero, 2005), planktonic production within ocean islands at these latitudes (Gove et al., 2016), promotes the coexistence of planktivorous fishes by partitioning resources across space and time.

Our quantitative synthesis of reef fish assemblages used a compilation of data. Although methods of fish counts were comparable, differences in transect dimension and inter-observer variability might have introduced certain biases (Kulbicki et al., 2010). However, our local diversity metrics statistically controlled for varying survey effort (i.e. total number of individuals sampled at a site), and sites within ecoregions that were surveyed with different transect dimensions (e.g. RLS data vs. scientific surveys) did not depart from the ecoregional pattern. Another caveat may be the lack of fine-scale habitat data, which might have contributed to the presence of weak spatial autocorrelation in the residuals of our models. Expansion of systematic methods of data collection for reef ecosystems that involve a combination of citizen scientist and academics, such as the RLS, represent a key step for advancing global biodiversity monitoring systems (Edgar et al., 2020). Lastly, we note that the coarse nature of traits selected (da Silva et al., 2019) and the large species pool (eastern Atlantic Ocean) used in the null models, might have underscored the importance of biotic mechanisms (e.g. competitive exclusion) driving reef fish assemblage structure (Münkemüller et al., 2020). In this context, the creation of open access repositories of reef fish traits (Parravicini et al., 2020), coupled with the application of novel frameworks that statistically control for the effect of 'environmental filtering' (de Bello et al., 2012), would advance our knowledge on biotic mechanisms underlying community assembly across global gradients.

Our study brings together long debated ecological mechanisms underpinning LDGs, and have important implications in an era of rapid biodiversity change (Blowes et al., 2019). Niche and neutral assembly mechanisms both contribute to the observed LDG in reef fish diversity, with a shifting importance from overdispersion at tropical to clustering at temperate ecoregions. We show that, despite these patterns can be predicted based on large-scale climatic and geographic variables, variation in local-scale factors (e.g. human population and depth) and high stochasticity in species abundances place challenges to understand and predict community dynamics in the face of increasing anthropogenic pressures. Climate warming, increased nutrient pollution, habitat loss and fisheries exploitation are all expected to alter community dynamics. By placing increasing niche constraints on biota, reshaping biological interactions, and driving local population collapses, understanding and forecasting their eco-evolutionary implications remains a critical knowledge gap to conserve the Earth's biological processes and services.

\section{ACKNOWLEDGEMENTS}

This study was partially supported by Portuguese national funds from FCT-Foundation for Science and Technology through project 
UIDB/04326/2020. C.R. and P.N. were financially supported by the Oceanic Observatory of Madeira Project (M1420-01-0145-FEDER000001-Observatório Oceânico da Madeira-OOM). D.A.S. was supported by a UKRI Future Leaders Fellowship (MR/S032827/1). P.J.M. was supported by a Marie Curie Career Integration Grant (PCIG10-GA-2011-303685). T.W. received funding from the Australian Research Council (DP170100023). We thank all RLS volunteer divers for their dedication and hard work in collecting parts of the data presented here. No specific permits were required for fieldwork and data collection.

\section{CONFLICT OF INTEREST}

There is no conflict of interest associated with this publication.

\section{DATA AVAILABILITY STATEMENT}

Data and $\mathrm{R}$ code used for the analyses can be downloaded from the author's GitHub repository (https://github.com/NestorBosch/Atlan tic_Reef_Fish_Diversity; https://doi.org/10.5281/zenodo.5094218; https://zenodo.org/badge/latestdoi/379161223).

\section{ORCID}

Nestor E. Bosch (D) https://orcid.org/0000-0003-0421-8456 Thomas Wernberg (D) https://orcid.org/0000-0003-1185-9745 Tim J. Langlois (D) https://orcid.org/0000-0001-6404-4000 Dan A. Smale (D) https://orcid.org/0000-0003-4157-541X Pippa J. Moore (D) https://orcid.org/0000-0002-9889-2216 João N. Franco (D) https://orcid.org/0000-0002-8249-5224 Pierre Thiriet (D) https://orcid.org/0000-0002-5254-5948 Cláudia Ribeiro (D) https://orcid.org/0000-0002-0703-8795 Pedro Neves (D) https://orcid.org/0000-0001-6659-0398 Rui Freitas (D) https://orcid.org/0000-0001-5822-2026 Karen Filbee-Dexter (1D) https://orcid.org/0000-0001-8413-6797 Kjell Magnus Norderhaug (D) https://orcid. org/0000-0001-6374-4275

Francisco Otero-Ferrer (D) https://orcid.org/0000-0002-1328-9662

Fernando Espino (D) https://orcid.org/0000-0003-3988-7297

Ricardo Haroun (D) https://orcid.org/0000-0003-1348-692X

Natali Lazzari (D) https://orcid.org/0000-0002-5546-3382

Fernando Tuya (D) https://orcid.org/0000-0001-8316-5887

\section{REFERENCES}

Almada, V. C., Toledo, J. F., Brito, A., Levy, A., Floeter, S. R., Robalo, J. I., Martins, J., \& Almada, F. O. (2013). Complex origins of the Lusitania biogeographic province and northeastern Atlantic fishes. Frontiers of Biogeography, 5(1). https://doi.org/10.21425/ F55114493

Arístegui, J., \& Montero, M. F. (2005). Temporal and spatial changes in plankton respiration and biomass in the Canary Islands region: The effect of mesoscale variability. Journal of Marine Systems, 54(1), 6582. https://doi.org/10.1016/j.jmarsys.2004.07.004

Barneche, D. R., Rezende, E. L., Parravicini, V., Maire, E., Edgar, G. J., StuartSmith, R. D., Arias-González, J. E., Ferreira, C. E. L., Friedlander, A. M., Green, A. L., Luiz, O. J., Rodríguez-Zaragoza, F. A., Vigliola, L., Kulbicki, M., \& Floeter, S. R. (2019). Body size, reef area and temperature predict global reef-fish species richness across spatial scales. Global
Ecology and Biogeography, 28(3), 315-327. https://doi.org/10.1111/ geb.12851

Barton, K. (2018). MuMIn: Multi-model inference. R package version 1.42.1. Retrieved from https://CRAN.R-project.org/packa ge $=$ MuMln

Bates, D., Mächler, M., Bolker, B., \& Walker, S. (2014). Fitting Linear Mixed-Effects Models using Ime4. arXiv [stat.CO]. arXiv. Retrieved from http://arxiv.org/abs/1406.5823

Bender, M. G., Leprieur, F., Mouillot, D., Kulbicki, M., Parravicini, V., Pie, M. R., Barneche, D. R., Oliveira-Santos, L. G. R., \& Floeter, S. R. (2017). Isolation drives taxonomic and functional nestedness in tropical reef fish faunas. Ecography, 40(3), 425-435. https://doi. org/10.1111/ecog.02293

Bender, M. G., Pie, M. R., Rezende, E. L., Mouillot, D., \& Floeter, S. R. (2013). Biogeographic, historical and environmental influences on the taxonomic and functional structure of Atlantic reef fish assemblages. Global Ecology and Biogeography, 22(11), 1173-1182. https:// doi.org/10.1111/geb.12099

Beukhof, E., Frelat, R., Pecuchet, L., Maureaud, A., Dencker, T. S., Sólmundsson, J., Punzón, A., Primicerio, R., Hidalgo, M., Möllmann, C., \& Lindegren, M. (2019). Marine fish traits follow fast-slow continuum across oceans. Scientific Reports, 9(1), 17878. https://doi. org/10.1038/s41598-019-53998-2

Blowes, S. A., Supp, S. R., Antão, L. H., Bates, A., Bruelheide, H., Chase, J. M., Blowes, S. A., Supp, S. R., Antão, L. H., Bates, A., Bruelheide, H., Chase, J. M., Moyes, F., Magurran, A., McGill, B., Myers-Smith, I. H., \& Winter, M. (2019). The geography of biodiversity change in marine and terrestrial assemblages. Science, 366(6463), 339-345.

Briggs, J. C., \& Bowen, B. W. (2013). Marine shelf habitat: Biogeography and evolution. Journal of Biogeography, 40(6), 1023-1035. https:// doi.org/10.1111/jbi.12082

Brown, J. H. (2014). Why are there so many species in the tropics? Journal of Biogeography, 41(1), 8-22. https://doi.org/10.1111/jbi.12228

Burnham, K. P., \& Anderson, D. R. (2003). Model selection and multimodel inference: A practical information-theoretic approach. Springer Science \& Business Media.

Cadotte, M. W., Albert, C. H., \& Walker, S. C. (2013). The ecology of differences: Integrating evolutionary and functional distances. Ecology Letters, 16, 1234-1244.

Cavender-Bares, J., Kozak, K. H., Fine, P. V. A., \& Kembel, S. W. (2009). The merging of community ecology and phylogenetic biology. Ecology Letters, 12(7), 693-715. https://doi. org/10.1111/j.1461-0248.2009.01314.x

Chang, J., Rabosky, D. L., Smith, S. A., \& Alfaro, M. E. (2019). An r package and online resource for macroevolutionary studies using the ray-finned fish tree of life. Methods in Ecology and Evolution, 10(7), 1118-1124.

Chao, A., Chiu, C.-H., \& Jost, L. (2014). Unifying species diversity, phylogenetic diversity, functional diversity, and related similarity and differentiation measures through hill numbers. Annual Review of Ecology, Evolution, and Systematics, 45(1), 297-324. https://doi. org/10.1146/annurev-ecolsys-120213-091540

Chao, A., Chiu, C.-H., Villéger, S., Sun, I.-F., Thorn, S., Lin, Y.-C., Chiang, J.-M., \& Sherwin, W. B. (2019). An attribute-diversity approach to functional diversity, functional beta diversity, and related (dis)similarity measures. Ecological Monographs, 89(2), e01343. https://doi. org/10.1002/ecm.1343

Chase, J. M., Biro, E. G., Ryberg, W. A., \& Smith, K. G. (2009). Predators temper the relative importance of stochastic processes in the assembly of prey metacommunities. Ecology Letters, 12(11), 12101218. https://doi.org/10.1111/j.1461-0248.2009.01362.x

Chaudhary, C., Richardson, A. J., Schoeman, D. S., \& Costello, M. J. (2021). Global warming is causing a more pronounced dip in marine species richness around the equator. Proceedings of the National Academy of Sciences of the United States of America, 118(15), e2015094118. https://doi.org/10.1073/pnas.2015094118 
Chaudhary, C., Saeedi, H., \& Costello, M. J. (2016). Bimodality of latitudinal gradients in marine species richness. Trends in Ecology \& Evolution, 31(9), 670-676. https://doi.org/10.1016/j.tree.2016.06.001

Chust, G., Villarino, E., Chenuil, A., Irigoien, X., Bizsel, N., Bode, A., Broms, C., Claus, S., Fernández de Puelles, M. L., Fonda-Umani, S., Hoarau, G., Mazzocchi, M. G., Mozetič, P., Vandepitte, L., Veríssimo, H., Zervoudaki, S., \& Borja, A. (2016). Dispersal similarly shapes both population genetics and community patterns in the marine realm. Scientific Reports, 6(1), 28730. https://doi.org/10.1038/srep28730

da Silva, V. E. L., Silva-Firmiano, L. P. S., Teresa, F. B., Batista, V. S., Ladle, R. J., \& Fabré, N. N. (2019). Functional traits of fish species: Adjusting resolution to accurately express resource partitioning. Frontiers in Marine Science, 6, 303. https://doi.org/10.3389/fmars.2019.00303

de Bello, F., Price, J. N., Münkemüller, T., Liira, J., Zobel, M., Thuiller, W., Gerhold, P., Götzenberger, L., Lavergne, S., Lepš, J., Zobel, K., \& Pärtel, M. (2012). Functional species pool framework to test for biotic effects on community assembly. Ecology, 93(10), 2263-2273. https://doi.org/10.1890/11-1394.1

Diniz-Filho, J. A. F., Bini, L. M., \& Hawkins, B. A. (2003). Spatial autocorrelation and red herrings in geographical ecology. Global Ecology and Biogeography, 12(1), 53-64. https://doi. $\operatorname{org} / 10.1046 / j .1466-822 X .2003 .00322 . x$

Duffy, J. E., Lefcheck, J. S., Stuart-smith, R. D., Navarrete, S. A., \& Edgar, G. J. (2016). Biodiversity enhances reef fish biomass and resistance to climate change. Proceedings of the National Academy of Sciences of the United States of America, 113(22), 6230-6235. https://doi. org/10.1073/pnas.1524465113

Edgar, G. J., Alexander, T. J., Lefcheck, J. S., Bates, A. E., Kininmonth, S. J., Thomson, R. J., Duffy, J. E., Costello, M. J., \& Stuart-Smith, R. D. (2017). Abundance and local-scale processes contribute to multiphyla gradients in global marine diversity. Science Advances, 3(10), e1700419. https://doi.org/10.1126/sciadv.1700419

Edgar, G. J., Cooper, A., Baker, S. C., Barker, W., Barrett, N. S., Becerro, M. A., Bates, A. E., Brock, D., Ceccarelli, D. M., Clausius, E., \& Davey, M. (2020). Reef life survey: Establishing the ecological basis for conservation of shallow marine life. Biological Conservation, 252, 108855 .

Ellingsen, K. E., Yoccoz, N. G., Tveraa, T., Frank, K. T., Johannesen, E., Anderson, M. J., Dolgov, A. V., \& Shackell, N. L. (2020). The rise of a marine generalist predator and the fall of beta diversity Global Change Biology, 26(5), 2897-2907. https://doi.org/10.1111/ gcb.15027

Floeter, S. R., Rocha, L. A., Robertson, D. R., Joyeux, J. C., Smith-Vaniz, W. F., Wirtz, P., Edwards, A. J., Barreiros, J. P., Ferreira, C. E., Gasparini, J. L., \& Brito, A. (2008). Atlantic reef fish biogeography and evolution. Journal of Biogeography, 35(1), 22-47.

Ford, B. M., \& Roberts, J. D. (2019). Functional traits reveal the presence and nature of multiple processes in the assembly of marine fish communities. Oecologia, 192(1), 143-154. https://doi.org/10.1007/ s00442-019-04555-1

Fox, R. J., \& Bellwood, D. R. (2013). Niche partitioning of feeding microhabitats produces a unique function for herbivorous rabbitfishes (Perciformes, Siganidae) on coral reefs. Coral Reefs, 32(1), 13-23. https://doi.org/10.1007/s00338-012-0945-5

Freitas, R., Romeiras, M., Silva, L., Cordeiro, R., Madeira, P., González, J. A., Wirtz, P., Falcón, J. M., Brito, A., Floeter, S. R., Afonso, P., Porteiro, F., Viera-Rodríguez, M. A., Neto, A. I., Haroun, R., Farminhão, J. N. M., Rebelo, A. C., Baptista, L., Melo, C. S., ... Ávila, S. P. (2019). Restructuring of the "Macaronesia" biogeographic unit: A marine multi-taxon biogeographical approach. Scientific Reports, 9(1), 15792. https://doi.org/10.1038/s41598-019-51786-6

Froese, R., \& Pauly, D. (2012). Fishbase (www database). World Wide Web Electronic Publications. Retrieved from http://www.fishbase.org

Gaboriau, T., Albouy, C., Descombes, P., Mouillot, D., Pellissier, L., \& Leprieur, F. (2019). Ecological constraints coupled with deep-time habitat dynamics predict the latitudinal diversity gradient in reef fishes.
Proceedings of the Royal Society B: Biological Sciences, 286(1911), 20191506. https://doi.org/10.1098/rspb.2019.1506

Galipaud, M., Gillingham, M. A. F., \& Dechaume-Moncharmont, F. X (2017). A farewell to the sum of Akaike weights: The benefits of alternative metrics for variable importance estimations in model selection. Methods in Ecology and Evolution, 8(12), 1668-1678. https:// doi.org/10.1111/2041-210X.12835

Gaston, K. J. (2000). Global patterns in biodiversity. Nature, 405(6783), 220-227.

Gotelli, N. J. (2000). Null model analysis of species co-occurrence patterns. Ecology, 81(9), 2606-2621. https://doi.org/10.1890/00129658(2000)081[2606:NMAOSC]2.0.CO;2

Gove, J. M., McManus, M. A., Neuheimer, A. B., Polovina, J. J., Drazen, J. C., Smith, C. R., Merrifield, M. A., Friedlander, A. M., Ehses, J. S., Young, C. W., Dillon, A. K., \& Williams, G. J. (2016). Near-island biological hotspots in barren ocean basins. Nature Communications, 7, 10581. https://doi.org/10.1038/ncomms10581

Hillebrand, H. (2004). On the generality of the latitudinal diversity gradient. The American Naturalist, 163(2), 192-211. https://doi. org/10.1086/381004

Hubbell, S. P. (2001). The unified neutral theory of biodiversity and biogeography (MPB-32). Princeton University Press.

Hubert, N., Paradis, E., Bruggemann, H., \& Planes, S. (2011). Community assembly and diversification in Indo-Pacific coral reef fishes. Ecology and Evolution, 1(3), 229-277. https://doi.org/10.1002/ ece3.19

Hutchinson, G. E. (1957). Concluding remarks. Cold Spring Harbor Symposia on Quantitative Biology, 22, 415-427. https://doi. org/10.1101/SQB.1957.022.01.039

Johansen, J. L., \& Jones, G. P. (2013). Sediment-induced turbidity impairs foraging performance and prey choice of planktivorous coral reef fishes. Ecological Applications, 23(6), 1504-1517. https://doi. org/10.1890/12-0704.1

Kembel, S. W., Cowan, P. D., Helmus, M. R., Cornwell, W. K., Morlon, H., Ackerly, D. D., Blomberg, S. P., \& Webb, C. O. (2010). Picante: $\mathrm{R}$ tools for integrating phylogenies and ecology. Bioinformatics, 26(11), 1463-1464. https://doi.org/10.1093/bioinformatics/ btq166

Kraft, N. J. B., Valencia, R., \& Ackerly, D. D. (2008). Functional traits and niche-based tree community assembly in an Amazonian forest. Science, 322(5901), 580-582.

Kulbicki, M., Cornuet, N., Vigliola, L., Wantiez, L., Moutham, G., \& Chabanet, P. (2010). Counting coral reef fishes: Interaction between fish life-history traits and transect design. Journal of Experimental Marine Biology and Ecology, 387(1), 15-23. https://doi. org/10.1016/j.jembe.2010.03.003

Lamanna, C., Blonder, B., Violle, C., Kraft, N. J. B., Sandel, B., Šimova, I., Donoghue, J. C., Svenning, J.-C., McGill, B. J., Boyle, B., Buzzard, V., Dolins, S., Jorgensen, P. M., Marcuse-Kubitza, A., Morueta-Holme, N., Peet, R. K., Piel, W. H., Regetz, J., Schildhauer, M., ... Enquist, B. J. (2014). Functional trait space and the latitudinal diversity gradient. Proceedings of the National Academy of Sciences of the United States of America, 111(38), 13745-13750. https://doi.org/10.1073/ pnas.1317722111

Leprieur, F., Colosio, S., Descombes, P., Parravicini, V., Kulbicki, M. Cowman, P. F., Bellwood, D. R., Mouillot, D., \& Pellissier, L. (2016). Historical and contemporary determinants of global phylogenetic structure in tropical reef fish faunas. Ecography, 39(9), 825-835. https://doi.org/10.1111/ecog.01638

Li, D. (2018). hillR: Taxonomic, functional, and phylogenetic diversity and similarity through Hill Numbers. Journal of Open Source Software, 3(31), 1041. https://doi.org/10.21105/joss.01041

Losos, J. B. (2008). Phylogenetic niche conservatism, phylogenetic signal and the relationship between phylogenetic relatedness and ecological similarity among species. Ecology Letters, 11(10), 995-1003. https://doi.org/10.1111/j.1461-0248.2008.01229.x 
Macarthur, R., \& Levins, R. (1967). The limiting similarity, convergence, and divergence of coexisting species. The American Naturalist, 101(921), 377-385. https://doi.org/10.1086/282505

MacArthur, R. H., \& Wilson, E. O. (2001). The theory of island biogeography. Princeton University Press.

Mayfield, M. M., \& Levine, J. M. (2010). Opposing effects of competitive exclusion on the phylogenetic structure of communities. Ecology Letters, 13(9), 1085-1093. https://doi. org/10.1111/j.1461-0248.2010.01509.x

Mcgill, B., Enquist, B., Weiher, E., \& Westoby, M. (2006). Rebuilding community ecology from functional traits. Trends in Ecology \& Evolution, 21(4), 178-185. https://doi.org/10.1016/j.tree.2006.02.002

McLean, M., Mouillot, D., Lindegren, M., Engelhard, G., Villéger, S., Marchal, P., Brind'Amour, A., \& Auber, A. (2018). A climatedriven functional inversion of connected marine ecosystems. Current Biology, 28(22), 3654-3660. https://doi.org/10.1016/j. cub.2018.09.050

McLean, M., Stuart-Smith, R. D., Villéger, S., Auber, A., Edgar, G. J., MacNeil, M. A., Loiseau, N., Leprieur, F., \& Mouillot, D. (2021). Trait similarity in reef fish faunas across the world's oceans. Proceedings of the National Academy of Sciences of the United States of America, 118(12), e2012318118. https://doi.org/10.1073/pnas.20123 18118

Montaño-Centellas, F. A., McCain, C., \& Loiselle, B. A. (2019). Using functional and phylogenetic diversity to infer avian community assembly along elevational gradients. Global Ecology and Biogeography, 29(2), 232-245. https://doi.org/10.1111/geb.13021

Mouillot, D., Villeger, S., Parravicini, V., Kulbicki, M., Arias-Gonzalez, J. E., Bender, M., Chabanet, P., Floeter, S. R., Friedlander, A., Vigliola, L., \& Bellwood, D. R. (2014). Functional over-redundancy and high functional vulnerability in global fish faunas on tropical reefs. Proceedings of the National Academy of Sciences of the United States of America, 111(38), 13757-13762. https://doi.org/10.1073/ pnas.1317625111

Mouquet, N., \& Loreau, M. (2003). Community patterns in sourcesink metacommunities. The American Naturalist, 162(5), 544-557. https://doi.org/10.1086/378857

Münkemüller, T., Gallien, L., Pollock, L. J., Barros, C., Carboni, M., Chalmandrier, L., Mazel, F., Mokany, K., Roquet, C., Smyčka, J., Talluto, M. V., \& Thuiller, W. (2020). Dos and don'ts when inferring assembly rules from diversity patterns. Global Ecology and Biogeography, 29(7), 1212-1229. https://doi.org/10.1111/ geb.13098

Nicholson, G. M., \& Clements, K. D. (2021). Ecomorphological divergence and trophic resource partitioning in 15 syntopic Indo-Pacific parrotfishes (Labridae: Scarini). Biological Journal of the Linnean Society, 132(3), 590-611. https://doi.org/10.1093/biolinnean/blaa210

Paradis, E., \& Schliep, K. (2019). ape 5.0: An environment for modern phylogenetics and evolutionary analyses in R. Bioinformatics, 35(3), 526-528.

Parravicini, V., Casey, J. M., Schiettekatte, N. M. D., Brandl, S. J., PozasSchacre, C., Carlot, J., Edgar, G. J., Graham, N. A. J., HarmelinVivien, M., Kulbicki, M., Strona, G., \& Stuart-Smith, R. D. (2020). Delineating reef fish trophic guilds with global gut content data synthesis and phylogeny. PLoS Biology, 18(12), e3000702. https:// doi.org/10.1371/journal.pbio.3000702

Pauly, D., Christensen, V., Guénette, S., Pitcher, T. J., Sumaila, U. R., Walters, C. J., Watson, R., \& Zeller, D. (2002). Towards sustainability in world fisheries. Nature, 418(6898), 689-695.

Pebesma, E. J. (2004). Multivariable geostatistics in S: The gstat package. Computers \& Geosciences, 30(7), 683-691. https://doi. org/10.1016/j.cageo.2004.03.012

Pecuchet, L., Törnroos, A., \& Lindegren, M. (2016). Patterns and drivers of fish community assembly in a large marine ecosystem. Marine Ecology Progress Series, 546, 239-248. https://doi.org/10.3354/ meps11613
Pellissier, V., Barnagaud, J.-Y., Kissling, W. D., Şekercioğlu, Ç., \& Svenning, J.-C. (2018). Niche packing and expansion account for species richness-productivity relationships in global bird assemblages. Global Ecology and Biogeography, 27(5), 604-615. https://doi. org/10.1111/geb.12723

Pérez-Ruzafa, A., Marcos, C., \& Bacallado, J. J. (2005). Biodiversidad marina en archipiélagos e islas: patrones de riqueza especıfica y afinidades faunısticas. Vieraea, 33, 455-475.

Polidoro, B. A., Ralph, G. M., Strongin, K., Harvey, M., Carpenter, K. E., Arnold, R., Buchanan, J. R., Camara, K. M. A., Collette, B. B., Comeros-Raynal, M. T., De Bruyne, G., Gon, O., Harold, A. S., Harwell, H., Hulley, P. A., Iwamoto, T., Knudsen, S. W., Lewembe, J. D. D., Linardich, C., ... Williams, A. (2017). The status of marine biodiversity in the Eastern Central Atlantic (West and Central Africa). Aquatic Conservation: Marine and Freshwater Ecosystems, 27(5), 1021-1034. https://doi.org/10.1002/aqc.2744

R Core Team (2019). R: A language and environment for statistical computing. R Foundation for Statistical Computing. https://www.R-proje ct.org/

Rabosky, D. L., Chang, J., Title, P. O., Cowman, P. F., Sallan, L., Friedman, M., Kaschner, K., Garilao, C., Near, T. J., Coll, M., \& Alfaro, M. E. (2018). An inverse latitudinal gradient in speciation rate for marine fishes. Nature, 559(7714), 392-395.

Ricklefs, R. E. (1987). Community diversity: Relative roles of local and regional processes. Science, 235(4785), 167-171.

Sale, P. F. (1977). Maintenance of high diversity in coral reef fish communities. The American Naturalist, 111(978), 337-359. https://doi. org/10.1086/283164

Sale, P. F. (1978). Coexistence of coral reef fishes? A lottery for living space. Environmental Biology of Fishes, 3(1), 85-102. https://doi. org/10.1007/BF00006310

Sbrocco, E. J., \& Barber, P. H. (2013). MARSPEC: Ocean climate layers for marine spatial ecology: Ecological Archives E094-086. Ecology, 94(4), 979. https://doi.org/10.1890/12-1358.1

Siqueira, A. C., Bellwood, D. R., \& Cowman, P. F. (2019). The evolution of traits and functions in herbivorous coral reef fishes through space and time. Proceedings of the Royal Society B, 286(1897), 20182672. https://doi.org/10.1098/rspb.2018.2672

Siqueira, A. C., Morais, R. A., Bellwood, D. R., \& Cowman, P. F. (2021). Planktivores as trophic drivers of global coral reef fish diversity patterns. Proceedings of the National Academy of Sciences of the United States of America, 118(9), 2019404118. https://doi.org/10.1073/ pnas. 2019404118

Spalding, M. D., Fox, H. E., Allen, G. R., Davidson, N., Ferdaña, Z. A., Finlayson, M., Halpern, B. S., Jorge, M. A., Lombana, A. L., Lourie, S. A., Martin, K. D., McManus, E., Molnar, J., Recchia, C. A., \& Robertson, J. (2007). Marine ecoregions of the world: A bioregionalization of coastal and shelf areas. BioScience, 57(7), 573-583. https://doi.org/10.1641/B570707

Stuart-Smith, R. D., Bates, A. E., Lefcheck, J. S., Duffy, J. E., Baker, S. C., Thomson, R. J., Stuart-Smith, J. F., Hill, N. A., Kininmonth, S. J., Airoldi, L., \& Becerro, M. A. (2013). Integrating abundance and functional traits reveals new global hotspots of fish diversity. Nature, 501(7468), 539-542.

Tittensor, D. P., Mora, C., Jetz, W., Lotze, H. K., Ricard, D., Berghe, E. V., $\&$ Worm, B. (2010). Global patterns and predictors of marine biodiversity across taxa. Nature, 466(7310), 1098-1101.

Tucker, C. M., Cadotte, M. W., Carvalho, S. B., Davies, T. J., Ferrier, S., Fritz, S. A., Grenyer, R., Helmus, M. R., Jin, L. S., Mooers, A. O., Pavoine, S., Purschke, O., Redding, D. W., Rosauer, D. F., Winter, M., \& Mazel, F. (2017). A guide to phylogenetic metrics for conservation, community ecology and macroecology. Biological Reviews of the Cambridge Philosophical Society, 92(2), 698-715. https://doi. org/10.1111/brv.12252

Tyberghein, L., Verbruggen, H., Pauly, K., Troupin, C., Mineur, F., \& De Clerck, O. (2012). Bio-ORACLE: A global 
environmental dataset for marine species distribution modelling. Global Ecology and Biogeography, 21(2), 272-281. https://doi. org/10.1111/j.1466-8238.2011.00656.x

Ulrich, W., \& Gotelli, N. J. (2013). Pattern detection in null model analysis. Oikos, 122(1), 2-18. https://doi. org/10.1111/j.1600-0706.2012.20325.x

Vellend, M. (2010). Conceptual synthesis in community ecology. The Quarterly Review of Biology, 85(2), 183-206. https://doi. org/10.1086/652373

Vellend, M., Srivastava, D. S., Anderson, K. M., Brown, C. D., Jankowski, J. E., Kleynhans, E. J., Kraft, N. J. B., Letaw, A. D., Macdonald, A. A. M., Maclean, J. E., Myers-Smith, I. H., Norris, A. R., \& Xue, X. (2014). Assessing the relative importance of neutral stochasticity in ecological communities. Oikos, 123(12), 1420-1430. https://doi. org/10.1111/oik.01493

Villéger, S., Brosse, S., Mouchet, M., Mouillot, D., \& Vanni, M. J. (2017). Functional ecology of fish: Current approaches and future challenges. Aquatic Sciences, 79(4), 783-801. https://doi.org/10.1007/ s00027-017-0546-z

Violle, C., Navas, M. L., Vile, D., Kazakou, E., Fortunel, C., Hummel, I., \& Garnier, E. (2007). Let the concept of trait be functional! Oikos, 116(5), 882-892. https://doi.org/10.1111/j.0030-1299.2007.15559.x

Webb, C. O., Ackerly, D. D., McPeek, M. A., \& Donoghue, M. J. (2002). Phylogenies and community ecology. Annual Review of Ecology and Systematics, 33(1), 475-505. https://doi.org/10.1146/annurev.ecols ys.33.010802.150448

Wiens, J. J., \& Graham, C. H. (2005). Niche conservatism: Integrating evolution, ecology, and conservation biology. Annual Review of Ecology, Evolution, and Systematics, 36(1), 519-539. https://doi.org/10.1146/ annurev.ecolsys.36.102803.095431

Willig, M. R., Kaufman, D. M., \& Stevens, R. D. (2003). Latitudinal gradients of biodiversity: Pattern, process, scale, and synthesis. Annual Review of Ecology, Evolution, and Systematics, 34(1), 273-309. https://doi.org/10.1146/annurev.ecolsys.34.012103.144032

Wood, S. (2006). Generalized additive models: An introduction with R. CRC Press.

Yeager, L. A., Deith, M. C. M., McPherson, J. M., Williams, I. D., Baum, J. K., \& Belmaker, J. (2017). Scale dependence of environmental controls on the functional diversity of coral reef fish communities. Global Ecology and Biogeography, 26(1), 1177-1189. https://doi. org/10.1111/geb.12628
Yeager, L. A., Marchand, P., Gill, D. A., Baum, J. K., \& McPherson, J. M. (2017). Marine socio-environmental covariates: Queryable global layers of environmental and anthropogenic variables for marine ecosystem studies. Ecology, 98(7), 1976. https://doi.org/10.1002/ ecy.1884

\section{BIOSKETCH}

My research focuses on understanding the mechanisms underpinning variation in the diversity and assemblage structure of reef fish communities across spatial and temporal scales, with a major focus on using trait-based approaches to understand how climate and other anthropogenic stressors modify key functions provided by reef fishes in coastal ecosystems.

Author contributions: N.E.B and F.T. conceived the idea; N.E.B. performed the statistical analyses and lead the writing; all authors contributed to data collection, as well as drafting and revising the manuscript for scientific content.

\section{SUPPORTING INFORMATION}

Additional supporting information may be found online in the Supporting Information section.

How to cite this article: Bosch, N. E., Wernberg, T., Langlois, T. J., Smale, D. A., Moore, P. J., Franco, J. N., Thiriet, P., Feunteun, E., Ribeiro, C., Neves, P., Freitas, R., Filbee-Dexter, K., Norderhaug, K. M., Garcla, A., Otero-Ferrer, F., Espino, F., Haroun, R., Lazzari, N., \& Tuya, F. (2021). Niche and neutral assembly mechanisms contribute to latitudinal diversity gradients in reef fishes. Journal of Biogeography, 48, 26832698. https://doi.org/10.1111/jbi.14237 